Review Article

\title{
Acid-Sensing Ion Channels as Potential Therapeutic Targets in Neurodegeneration and Neuroinflammation
}

\author{
Audrey Ortega-Ramírez, Rosario Vega, and Enrique Soto \\ Instituto de Fisiología, Benemérita Universidad Autónoma de Puebla, 14 sur 6301, CU, San Manuel, 72570 Puebla, PUE, Mexico \\ Correspondence should be addressed to Enrique Soto; esoto24@gmail.com
}

Received 26 March 2017; Revised 29 July 2017; Accepted 13 August 2017; Published 19 September 2017

Academic Editor: Maria Rosaria Catania

Copyright @ 2017 Audrey Ortega-Ramírez et al. This is an open access article distributed under the Creative Commons Attribution License, which permits unrestricted use, distribution, and reproduction in any medium, provided the original work is properly cited.

\begin{abstract}
Acid-sensing ion channels (ASICs) are a family of proton-sensing channels that are voltage insensitive, cation selective (mostly permeable to $\mathrm{Na}^{+}$), and nonspecifically blocked by amiloride. Derived from 5 genes (ACCN1-5), 7 subunits have been identified, $1 \mathrm{a}, 1 \mathrm{~b}, 2 \mathrm{a}, 2 \mathrm{~b}, 3,4$, and 5 , that are widely expressed in the peripheral and central nervous system as well as other tissues. Over the years, different studies have shown that activation of these channels is linked to various physiological and pathological processes, such as memory, learning, fear, anxiety, ischemia, and multiple sclerosis to name a few, so their potential as therapeutic targets is increasing. This review focuses on recent advances that have helped us to better understand the role played by ASICs in different pathologies related to neurodegenerative diseases, inflammatory processes, and pain.
\end{abstract}

\section{Introduction}

Extracellular acidification occurs in pathological situations, such as inflammation and brain ischemia, as well as under normal physiological conditions, such as neuronal activity and synaptic transmission. However, $\mathrm{pH}$ oscillations are closely regulated and confined to microdomains. Increased metabolism of carbohydrates produces a $\mathrm{pH}$ drop through products, such as lactic acid and $\mathrm{CO}_{2}$, activating $\mathrm{HCO}_{3}^{-}$ and $\mathrm{Na}^{+} / \mathrm{H}^{+}$exchangers that contribute to the regulation of $\mathrm{pH}[1]$.

The $\mathrm{pH}$ fluctuations affect many cellular processes, including enzymatic activity, membrane receptors, ion channel flow, and membrane transporters $[2,3]$. Because $\mathrm{pH}$ is a strictly regulated variable in multicellular organisms, localized $\mathrm{pH}$ changes may constitute significant signals of cellular processes that occur in a cell or a group of cells. Extracellular $\mathrm{pH}$ changes that occur in microdomains are sensed through acid-sensing ion channels (ASICs), which are membrane channels that are specifically activated by protons $\left(\mathrm{H}^{+}\right)$and produce a large, inward, mostly $\mathrm{Na}^{+}$current.

For accurate proton-mediated signaling, tight extracellular $\mathrm{pH}$ regulation is essential; failure of the $\mathrm{pH}$ buffering systems may lead to noisy activation of the system and no signal at all [4]. Recent works have shown that protons are mediators and ASICs are receptors in some synapses in the central nervous system (CNS) $[5,6]$. The proton-mediated signaling mechanism was first demonstrated in intestinal-muscular cells from C. elegans, where extracellular acidification occurs due to activation of an $\mathrm{Na}^{+} / \mathrm{H}^{+}$exchanger and $\mathrm{H}^{+}$activates a Cys-loop ionic channel (a specific proton receptor) that ultimately produces a muscle contraction [7].

In higher organisms, proton-mediated signaling has been found to mediate fear-conditioned learning, retinal cell activation, cochlear and vestibular afferent neuron synaptic activation, and synaptic transmission in the calyx of Held in the auditory system [8-12].

ASICs form part of the degenerin/epithelial sodium channel (DEG/ENaC) super family [13]. They are voltageinsensitive, cation-selective channels that are mostly permeable to $\mathrm{Na}^{+}$and nonspecifically blocked by amiloride. Seven different subunits, $1 \mathrm{a}, 1 \mathrm{~b}, 2 \mathrm{a}, 2 \mathrm{~b}, 3,4$ and 5 ( $\mathrm{a}$ and $\mathrm{b}$ refer to splice variants), derived from 5 genes (ACCN1-5) have been identified in mammals. ASICs typically generate transient inward currents in response to increments in the $\mathrm{H}^{+}$ 


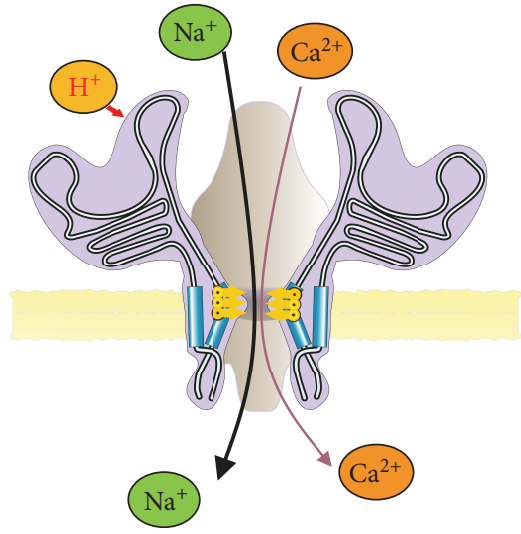

(a)
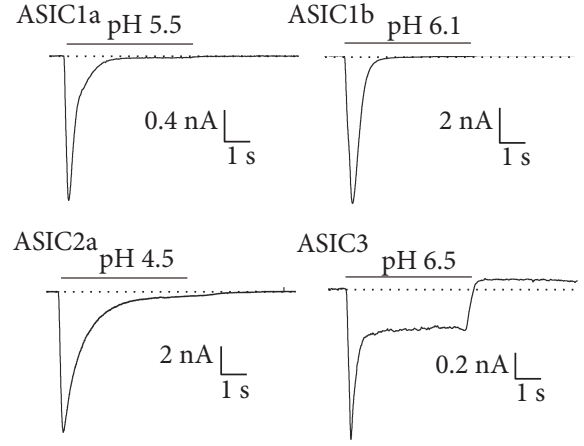

(b)
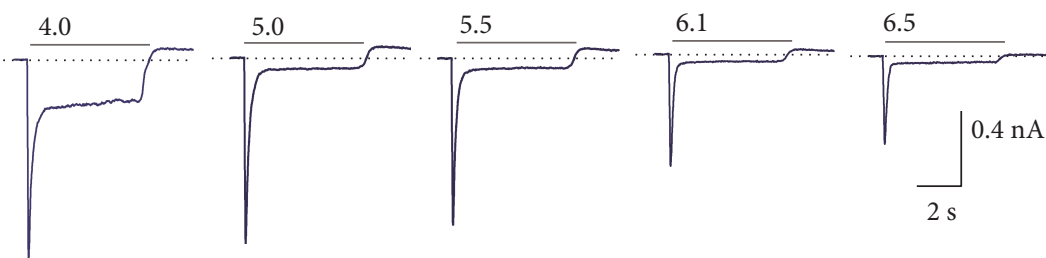

(c)

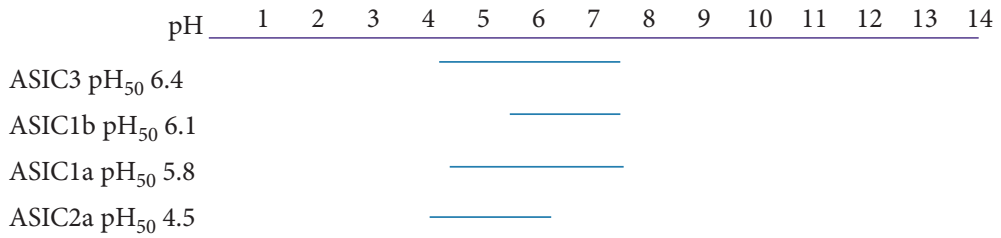

(d)

FIgURE 1: ASIC structure and properties. In (a) scheme of the ASIC trimer. Current is activated by $\mathrm{H}^{+}$and carried by Na ${ }^{+}$and in lower proportion by $\mathrm{Ca}^{2+}$. The increase in intracellular $\mathrm{Na}^{+}$and $\mathrm{Ca}^{2+}$ concentrations caused by ASIC current may activate various intracellular messenger systems. In (b), typical ASIC currents obtained from homomers of ASIC subunits transfected in Chinese hamster ovary (CHO) cells [229]. It is worth to note the sustained component of ASIC3 current. In (c), ASIC currents elicited by different pHs in isolated neurons from the rat spiral ganglion [11]. In (d), every subunit has a typical half-activation $\mathrm{pH}$. The various isoforms of ASIC confer the heteromeric channels a larger span of $\mathrm{pH}$ responsiveness. Calibration of currents is in nanoampere (nA) versus time in seconds (s).

concentration of the extracellular media and constitute the sensing element in proton-mediated signaling systems. It is worth to mention that desensitization of the current must probably constitute a protective mechanism in order to avoid sustained activation of the ASIC current in case of persistent acid $\mathrm{pH}$ shifts.

Each ASIC subunit consists of two transmembrane domains (TM1 and TM2), a large cysteine-rich extracellular loop and short intracellular N- and C-termini (Figure 1(a)) $[14,15]$. ASICs are widely expressed by many tissues, either in the nervous system or outside the nervous system (see Table 1 for a summary of the distribution and functions of ASICs).

Most ASIC subunits aggregate and form heteromultimers, generating diverse proton-gated channels that act as acid sensors spanning a large $\mathrm{pH}$ range $[16,17]$. ASIC4 and ASIC5 are the least studied of these proton-gated channels and are considered to be orphan subunits $[18,19]$. Both of them, however, are expressed in the central nervous system.
The crystal structure of the chicken ASICla protein demonstrated that functional ASICs are trimeric assemblies $[14,15]$. Recent evidence has put this into question; however, data from biochemical studies suggest that a tetrameric conformation of ASICs is also possible [20].

ASICla homomers and ASIC1a-ASIC2b heteromers have higher $\mathrm{Ca}^{2+}$ permeability; thus, sustained activation of these channels may raise intracellular $\mathrm{Ca}^{2+}$ concentrations in neurons [21-23], although recent evidence indicates that the $\mathrm{Ca}^{2+}$ permeability of ASICs is of marginal relevance [24].

The function of ASICs depends on their heteromeric composition. For example, the ASIC3 subunit is not expressed by neurons in the cortex or any brain nuclei but is expressed in a transgenic mouse model in which ASIC3 expression is induced in the whole brain, leading to impairment of ASIC-related behaviors, such as fear conditioning. This action may be due to changes that are produced in the biophysical properties of brain ASICs, indicating that the subunit composition and current kinetics are critical for the integration and processing of ASIC-related behaviors [25]. 
TABLE 1: Distribution and functions of ASICs.

\begin{tabular}{|c|c|c|c|}
\hline Subunit & Distribution & Physiology & Pathophysiology \\
\hline la & $\begin{array}{c}\text { Brain [29], spinal cord [117], DRG [3], TG [128], } \\
\text { NG [132], cochlear and vestibular neurons } \\
\text { [9,11,162], retina [8], astrocytes [163], lung } \\
\text { epithelial cells [164], vascular smooth muscle } \\
\text { cells [165], microglia [84], bone [166], taste } \\
\text { receptor cells [167] }\end{array}$ & $\begin{array}{c}\text { Synaptic plasticity [168], learning and } \\
\text { memory [168], fear conditioning [169], } \\
\text { visual transduction [8], visceral } \\
\text { mechanoperception, primary muscle } \\
\text { hyperalgesia [143], apoptosis [170], } \\
\text { chondroprotection and bone } \\
\text { resorption [171] }\end{array}$ & $\begin{array}{l}\text { Pain [88], inflammation [172], } \\
\text { migraine [124], epilepsy [46], hepatic } \\
\text { fibrosis [173], multiple sclerosis [32], } \\
\text { Parkinson [174], Huntington [175], } \\
\text { anxiety [176], depression [177], } \\
\text { growth and migration of gliomas } \\
\text { [178], excitotoxicity [179] }\end{array}$ \\
\hline $1 b$ & $\begin{array}{c}\text { DRG [3], immune cells [31], taste receptor } \\
\text { cells [180], carotid body [181], and cochlear } \\
\text { hair cells (stereocilia) [182] }\end{array}$ & & $\begin{array}{l}\text { Pain [118], inflammation }[31,143] \text {, } \\
\text { cancer }[78]\end{array}$ \\
\hline $2 \mathrm{a}$ & $\begin{array}{c}\text { Brain [117], DRG [3], NG [183], spinal cord } \\
\text { [117], retina [8], cochlear and vestibular neurons } \\
\text { [9,11], astrocytes [163], microglia [84], bone } \\
{[166], \text { lung epithelial cells [164], vascular smooth }} \\
\text { cells [165], taste receptor cells [167], carotid } \\
\text { body [181] }\end{array}$ & $\begin{array}{l}\text { Visual transduction [8], detection of } \\
\text { sour taste [184], mechanosensation } \\
\text { [185], arterial baroreceptor reflex [186] }\end{array}$ & $\begin{array}{l}\text { Inflammation [84], ischemia [187], } \\
\text { migration of gliomas [75] }\end{array}$ \\
\hline $2 b$ & $\begin{array}{l}\text { Brain [29], spinal cord [188], DRG [3], NG } \\
\text { [183], JG [183], cochlear neurons [11], } \\
\text { retina [189], and taste receptors [190] }\end{array}$ & $\begin{array}{l}\text { Integrity of retina [8], modulator } \\
\text { of ASIC1a, ASIC1b, ASIC2a, and } \\
\text { ASIC3 [23] }\end{array}$ & $\begin{array}{c}\text { Inflammation [84], gastrointestinal } \\
\text { pain [128] }\end{array}$ \\
\hline 3 & $\begin{array}{c}\text { DRG [3], TG [128], cochlear and vestibular } \\
\text { neurons [9, 11], vagal and glossopharyngeal } \\
\text { ganglia [183], brain [29], spinal cord [188], } \\
\text { retina [191], taste receptors [167], astrocytes, } \\
\text { microglia [84], testis [192], chondrocytes and } \\
\text { synoviocytes [115], adipocytes [163], immune } \\
\text { cells [31], lung epithelial cells [164], bone [166], } \\
\text { cartilage [166], teeth [193], vascular smooth } \\
\text { muscle [165], and carotid body [181] }\end{array}$ & $\begin{array}{l}\text { Chemoreception [181], skin } \\
\text { mechanosensory [139], auditory } \\
\text { and visual processing [191], } \\
\text { mechanosensory of the intestinal } \\
\text { tract [128] }\end{array}$ & $\begin{array}{l}\text { Pain [85], inflammation [85], epilepsy } \\
\text { [47], migraine [122], gastrointestinal } \\
\text { pain [128], cardiac pain [63], } \\
\text { postoperatory pain [109], secondary } \\
\text { mechanical hyperalgesia [142] }\end{array}$ \\
\hline 4 & $\begin{array}{l}\text { Brain [194], spinal cord [117], pituitary } \\
\text { gland [195], immune cells [31], and } \\
\text { retina [196] }\end{array}$ & $\begin{array}{l}\text { A possible function is to decrease the } \\
\text { amount of functional ASICs in the } \\
\text { plasma membrane and as a regulator } \\
\text { of pain [197] }\end{array}$ & Pain [197] \\
\hline
\end{tabular}

DRG: dorsal root ganglia; TG: trigeminal ganglia; NG: nodal ganglia; SG: spiral ganglia; JG: jugular ganglia.

ASICs typically generate transient inward currents that mostly desensitize, although specific channels show some level of sustained acid-dependent current (Figures 1(b) and $1(c))[17,26]$. Mild or slow acidification may result in steady-state desensitization, even at $\mathrm{pH}$ 7.4, and a significant channel population becomes desensitized [27].

The precise concentration of protons required to induce channel activation varies between subunits. Typically, in homomeric channels, the most sensitive subunit is ASIC3, which has a half-activation $\mathrm{pH}\left(\mathrm{pH}_{50}\right)$ of 6.4 , and ASIC1b, which has a $\mathrm{pH}_{50}$ of 6.1. ASIC2a is less sensitive and has a $\mathrm{pH}_{50}$ of 4.5 , although its $\mathrm{pH}$ sensitivity could change because it is subject to endogenous neuromodulators [17, 28]. The set of different ASIC subunit sensitivities allows to discriminate extracellular $\mathrm{pH}$ changes from a very acidic $\mathrm{pH}$ (approximately 4.0) to a $\mathrm{pH}$ of up to $7.8[17,29]$, thus covering a significant range of $\mathrm{pH}$ that are relevant for biological processes (Figure 1(d)).

Amiloride, di- and trivalent cations $\left(\mathrm{Pb}^{2+}\right.$ and $\left.\mathrm{Gd}^{3+}\right)$ and toxins from anemones, tarantulas, and snakes are examples of molecules that act on ASICs that have become the focus of intensive pharmacological research (see Tables 2 and 3 for a summary of ASIC modulator molecules).

\section{ASICs in Neurodegenerative Disease}

2.1. Multiple Sclerosis. Multiple sclerosis (MS) is a chronic autoimmune inflammatory disease of the CNS, whose pathophysiological process involves demyelination and axonal degeneration [30].

In experimental autoimmune encephalomyelitis (EAE), a mouse model of MS, it was found that the ASIC1 knockout mice showed reduced clinical deficits and axonal degeneration compared with wild-type mice. Furthermore, amiloride produced significant protection in animals with EAE [31].

ASIC1a activation triggers the intracellular accumulation of $\mathrm{Na}^{+}$and $\mathrm{Ca}^{2+}$, and previous studies have shown that excessive accumulation of these ions is involved in neuronal degeneration and inflammatory processes in MS [31]. ASIC1 was found to be upregulated in axons and oligodendrocytes in EAE animals, and coincidently, in patients with active MS, a correlation was demonstrated between increased ASIC1 expression and axon injury markers [32]. Moreover, 
TABle 2: Exogenous modulators.

\begin{tabular}{|c|c|c|c|}
\hline & Compound & Effect & Subunit \\
\hline \multirow{8}{*}{$\begin{array}{l}\text { Toxins from } \\
\text { venoms }\end{array}$} & PcTx1 & $\begin{array}{l}\uparrow \text { the affinity of the proton, desensitizes the } \\
\text { channel [198] }\end{array}$ & ASIC1a, 1a-2b \\
\hline & Hila & $\begin{array}{l}\text { Stabilizes the close state of the channel, impeding } \\
\text { the transition into a conducting state [199] }\end{array}$ & ASICla \\
\hline & APTx2 & $\downarrow$ ASIC3 and ASIC3 heteromers [200] & ASIC3 \\
\hline & MitTx & $\begin{array}{c}\uparrow \text { increase the sensitivity of ASIC2a to protons } \\
\text { and activate ASIC1a, 1b, and } 3[92]\end{array}$ & ASIC1a, $1 b, 2 a$, and 3 \\
\hline & Mambalgins & $\begin{array}{l}\downarrow \text { potent, rapid, and reversible inhibitor } \\
\text { of ASICs [86]. }\end{array}$ & $\begin{array}{l}\text { ASIC1a, 1b, 1a-2a, } \\
1 \mathrm{a}-2 \mathrm{~b} \text {, and } 1 \mathrm{a}-1 \mathrm{~b}\end{array}$ \\
\hline & Ugr 9-1 & $\begin{array}{l}\downarrow \text { ASIC3 current, including sustained } \\
\text { component [201] }\end{array}$ & ASIC3 \\
\hline & PhcrTx1 & $\downarrow$ ASICs in nDRG [202] & All subunits \\
\hline & $\alpha$-Dendrotoxin & $\downarrow$ ASICs in nDRG [203] & $?$ \\
\hline \multirow{9}{*}{$\begin{array}{l}\text { Vegetal } \\
\text { compounds }\end{array}$} & Thalassiolin B & $\downarrow$ ASICs in nDRG [204] & $\begin{array}{c}\text { Currents with } \\
\text { desensitization }<400 \mathrm{~ms}\end{array}$ \\
\hline & Sevanol & $\begin{array}{l}\downarrow \text { ASIC1a and } 3 \text { (including sustained } \\
\text { component) [205] }\end{array}$ & ASIC1a and 3 \\
\hline & Gastrodin & $\downarrow$ ASICs in nDRG [206] & All subunits \\
\hline & Puerarin & $\begin{array}{l}\downarrow \text { ASICs in rat hippocampal neurons and } \\
\text { homomers [67] }\end{array}$ & ASICla \\
\hline & Chlorogenic acid & $\downarrow$ ASICs in nDRG [207] & All subunits \\
\hline & Morphine & $\downarrow$ ASICs in nDRG [208] & All subunits \\
\hline & Paeoniflorin & $\downarrow$ ASICs in PC12 cell line [38] & ASIC1a \\
\hline & Ligustrazine & $\downarrow$ ASICs in nDRG and ASIC heteromers [134] & ASIC1a, $1 b, 2 a$, and 3 \\
\hline & Cannabinoids & $\downarrow$ ASICs in nDRG [209] & All subunits \\
\hline \multirow[t]{2}{*}{ NSAIDs } & $\begin{array}{l}\text { Salicylic acid, aspirin, diclofenac, } \\
\text { fluribuprofen, ibuprofen, peroxicam }\end{array}$ & $\begin{array}{c}\downarrow \text { homomers and heteromers of ASIC1a, } \\
2 \mathrm{a} \text {, and } 3[210]\end{array}$ & ASIC1a, $2 \mathrm{a}$, and 3 \\
\hline & CHF5074 & $\downarrow$ ASICs in CA1 pyramidal neurons [211] & ASIC1a \\
\hline \multirow{3}{*}{ Anesthetics } & Tetracaine & $\downarrow$ homomeric ASICs and ASICs in nDRG [212] & ASIC1a, $1 b$, and 3 \\
\hline & Lidocaine & $\downarrow$ ASIC1a and heteromers $[213]$ & ASICla and heteromers \\
\hline & Propofol & $\downarrow$ ASICs in nDRG [214] & All subunits \\
\hline Aminoglycosides & Streptomicyn, neomicyn, gentamicyn & $\downarrow$ ASICs in nDRG [87] & All subunits \\
\hline \multirow{4}{*}{ Monoamines } & 9-Aminoacridine (9AA) & $\begin{array}{l}\downarrow \text { ASICs in rat hippocampal neurons and } \\
\text { homomers [215] }\end{array}$ & ASIC1a and ASIC3 \\
\hline & Memantine & $\begin{array}{l}\downarrow \text { ASICs in hippocampal neurons and } \\
\text { homomers [215] }\end{array}$ & ASIC1a, 2a, and 3 \\
\hline & IEM1921 & $\begin{array}{l}\uparrow \text { ASICs in rat hippocampal neurons, } \downarrow \text { ASIC3 } \\
\text { current and potentiated the steady state }[215]\end{array}$ & ASIC1a, ASIC3 \\
\hline & IEM2117 & $\begin{array}{c}\uparrow \text { ASICs in hippocampal neurons and } \\
\text { homomers [215] }\end{array}$ & ASIC1a, 2a \\
\hline \multirow{8}{*}{ Others } & Amiloride & $\downarrow$ unspecific inhibitor of ASIC subunits [13] & All subunits \\
\hline & 4-Chlorophenylguanidine & $\begin{array}{l}\text { Activating the channel and increasing } \\
\text { proton sensitivity [216] }\end{array}$ & ASIC3 \\
\hline & GMQ & $\uparrow$ ASIC3 homomers at neutral pH [82] & ASIC3 \\
\hline & Tetraethylammonium (TEA) & $\downarrow$ heteromeric ASIC currents [23] & ASIC1a-2b \\
\hline & 4-Aminopyridine (4AP) & $\downarrow$ heteromeric ASIC currents [217] & ASIC1a-2a and $1 \mathrm{a}-2 \mathrm{~b}$ \\
\hline & A-317567 & $\downarrow$ ASICs in nDRG [93] & All subunits \\
\hline & Nafamostat mesilate & $\downarrow$ ASIC currents $[218]$ & ASIC1a, 2a, and 3 \\
\hline & Diarylamidines & $\begin{array}{l}\downarrow \text { ASICs in hippocampal neurons and } \\
\text { heteromers [219] }\end{array}$ & ASIC1a, 1b, 2a, and 3 \\
\hline
\end{tabular}


TABLE 2: Continued.

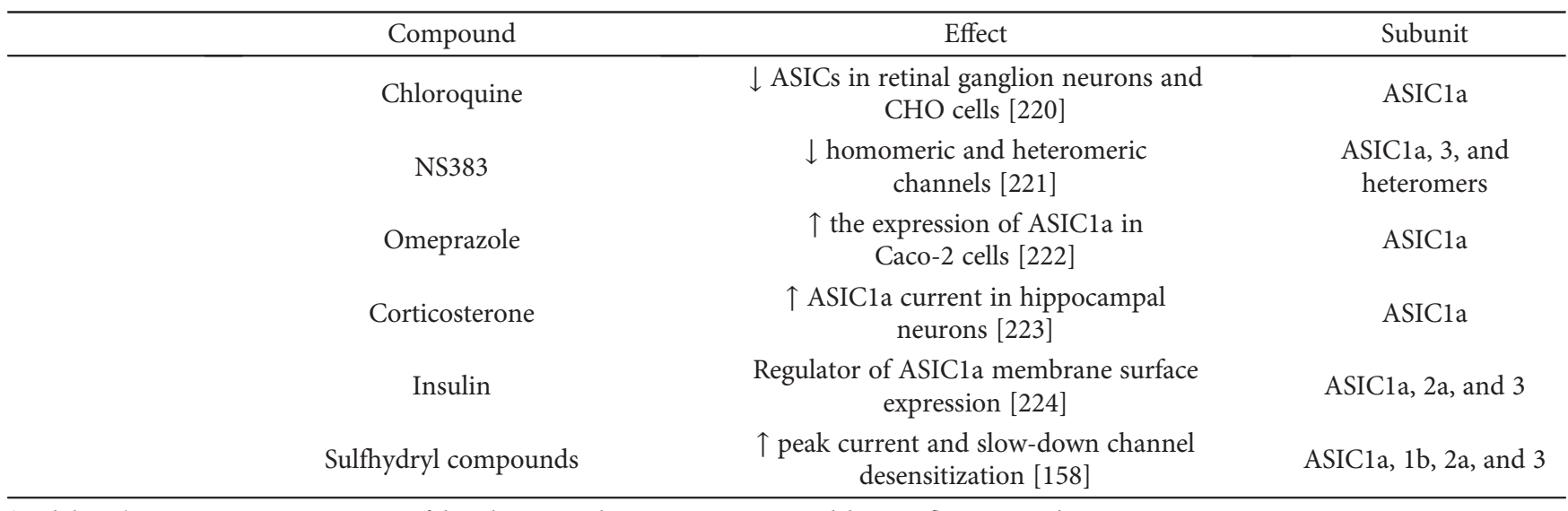

$\downarrow$ : inhibits; $\uparrow$ : increases; nDGR: neurons of dorsal root ganglia; NSAIDs: nonsteroidal anti-inflammatory drugs.

TABLE 3: Endogenous modulators.

\begin{tabular}{|c|c|c|c|}
\hline & Compound & Effect & Subunit \\
\hline \multirow{2}{*}{ Neuropeptides } & Dynorphin A, big dinorphin & $\begin{array}{c}\downarrow \text { decrease proton sensitivity of steady-state } \\
\text { inactivation }[65]\end{array}$ & ASIC1a \\
\hline & $\begin{array}{l}\text { FMRFamide and related mammalian } \\
\text { FF amide peptides. }\end{array}$ & $\begin{array}{c}\uparrow \text { enhance the sustained current and slow down } \\
\text { inactivation [225] }\end{array}$ & $\begin{array}{l}\text { ASIC1a, ASIC1b, } \\
\text { and ASIC3 }\end{array}$ \\
\hline \multirow{6}{*}{$\begin{array}{l}\text { Inflamatory } \\
\text { mediators }\end{array}$} & Nerve grow factor (NGF) & $\uparrow$ ASIC3 expression associated with hyperalgesia [81] & ASIC3 \\
\hline & Bradiquinine & $\uparrow$ ASIC mRNA levels $[81]$ & ASIC1a, $1 b, 2 b$, and 3 \\
\hline & Serotonin & $\uparrow$ ASIC3 sustained current [101] & \\
\hline & Interleucine & $\uparrow$ ASIC mRNA [81] & ASIC1a, $1 b, 2 b$, and 3 \\
\hline & Arachidonic acid & $\uparrow$ peak current $[106]$ & \\
\hline & Nitric oxide (NO donors) & $\uparrow$ increase ASIC1a, $1 \mathrm{~b}$, and 3 current $[55,107]$ & \\
\hline \multirow{3}{*}{ Cations } & $\begin{array}{c}\mathrm{Ca}^{2+}, \mathrm{Mg}^{2+}, \mathrm{Cd}^{2+}, \mathrm{Cu}^{2+}, \mathrm{Gd}^{3+} \\
\mathrm{Ni}^{2+}, \mathrm{Pb}^{2+}, \mathrm{Ba}^{2+}\end{array}$ & $\downarrow$ decrease the ASIC conductance $[160]$ & All subunits \\
\hline & $\mathrm{Zn}^{2+}$ & $\begin{array}{c}\downarrow \uparrow \text { dual effect: at low concentration } \downarrow \text { the current and } \\
\text { high concentration } \uparrow \text { the current }[226]\end{array}$ & $\begin{array}{l}\text { ASIC1a, 1a-2a, } \\
\text { and ASIC2a }\end{array}$ \\
\hline & $\mathrm{NH}_{4}^{+}$ & $\begin{array}{c}\uparrow \text { activate ASIC current at } \\
\text { extracellular } \mathrm{pH} 7.4[35]\end{array}$ & ASIC1a \\
\hline \multirow[t]{2}{*}{ Polyamines } & Spermine & $\begin{array}{l}\uparrow \text { activity of ASICs by shifting the steady-state } \\
\text { inactivation to more acid values [66] }\end{array}$ & ASICla and $1 \mathrm{~b}$ \\
\hline & Agmantine and arcaine & $\uparrow$ activate ASIC3 current $[82,83]$ & ASIC3 \\
\hline \multirow{4}{*}{ Others } & Lactate & $\uparrow$ ASIC current [63] & ASICla and 3 \\
\hline & ATP & $\uparrow \mathrm{pH}$ sensitivity of ASIC3 [105] & ASIC3 \\
\hline & $\mathrm{Cl}^{-}$ & $\begin{array}{l}\uparrow \text { slow down the rapid desensitization of ASIC1a and } \\
\text { maintains tachyphylaxis [227] }\end{array}$ & ASIC1a \\
\hline & $\mathrm{H}_{2} \mathrm{O}_{2}$ & $\downarrow$ ASIC1a current $[228]$ & ASIC1a \\
\hline
\end{tabular}

amiloride administration (ASIC-unspecific blocker) attenuated myelin and neuronal damage in animal models as well as in a cohort of MS patients, indicating that amiloride is neuroprotective and could be added to the pharmacological scheme in patients with MS [33].

2.2. Parkinson's Disease. Parkinson's disease (PD) is a disabling disease that is characterized by motor impairment, development of Lewy bodies (a pathological hallmark), and progressive loss of dopaminergic neurons in the substantia nigra [34].

Neurons in the substantia nigra express at least ASIC1a $[35,36]$. In a mouse model of PD induced by 1-methyl-4phenyl-1,2,3,6-tetrahydropyridine (MPTP), amiloride and psalmotoxin-1 (PcTx1; see Table 2) protect neurons from degeneration [36].

Furthermore, mutations of the Parkin gene or a lack of endogenous Parkin protein produces abnormal ASIC 
currents and dopaminergic neuronal injury, suggesting that ASIC activity may play a significant role in PD physiopathology [37].

Additionally, paeoniflorin, the principal active ingredient extracted from the root of Paeoniae alba, a natural product used in traditional medicine for the treatment of neurodegenerative disorders, blocks ASIC current and also has a neuroprotective effect in $\mathrm{PD}$ patients. Paeoniflorin reduces acidosis-induced accumulation of $\alpha$-synuclein (the major component of Lewy bodies); this latter effect could be linked to the inhibition of ASICs, most likely ASIC1a [38].

2.3. Epileptic Seizure Activity. During and following seizures, great quantities of lactic acid and glutamic acid are released into the extracellular space, causing a significant fall in $\mathrm{pH}$ that activates ASICs [39-41]. In animals treated with pilocarpine to induce a status epilepticus, a decrease of ASIC2b mRNA in all hippocampal areas and of ASIC1a mRNA in the CA1-2 was found [42].

Other studies showed that amiloride has anticonvulsant effects in vivo, suggesting that ASICs activation might have a proconvulsant potential [43-45]. Amiloride also blocks other ion channels (such as $\mathrm{ENaC}$ and T-type $\mathrm{Ca}^{2+}$ channels) and membrane exchangers; thus, the action of amiloride is not directly attributable to ASICs blockade.

By contrast, Ziemann and colleagues found that ASIC1a expression is higher in GABAergic interneurons than in excitatory neurons and showed that kainate-induced seizures were longer and more severe in ASIC1 knockout mice, although it did not affect the seizure threshold [46]. Consistent with the proposal that ASICs participate in ending seizures, the loss of ASIC1a reduced postictal depression [46].

Although ASIC3 expression in the brain is considered to be low or null, some reports described its expression in inhibitory GABAergic interneurons and glial cells [47]. Blocking ASIC3 with its specific antagonist APETx2 in pilocarpineinduced or pentylenetetrazole- (PTZ-) induced seizures shortened the latency to seizure and increased the incidence of generalized tonic-clonic seizures compared to the control group, indicating, as suggested for ASIC1a, that ASIC3 could participate in seizure ending [47].

Evidence also indicates that seizure-induced oxidative stress enhanced expression of the ASIC2a-containing channels that contribute to hyperexcitability, excitotoxicity, and eventually spontaneous seizures. Inhibition of ASICs was neuroprotective in the acute phase after seizure activity [48].

2.4. Ischemic Neuronal Injury. During a stroke, the disruption of blood flow to the brain deprives cells of energy and disturbs the cell's ionic homeostasis. Under these conditions, hypoxia enhances anaerobic glycolysis, resulting in the buildup of lactic acid and subsequent tissue acidosis [49, 50]. The extracellular $\mathrm{pH}$ in the brain typically drops to values below 6.5 or less during ischemia under normoglycemic conditions, activating ASIC currents [51, 52].

ASICs activation seems to play a fundamental role in acidosis-mediated neuronal injury. ASICla activation may trigger membrane depolarization, driving $\mathrm{Ca}^{2+}$ influx via
ASIC1a homomers or ASIC1a-ASIC2b heteromers, voltagegated $\mathrm{Ca}^{2+}$ channels, and NMDA receptors [21, 22, 53-57].

In cultured mouse and human cortical neurons, activation of ASICs induces glutamate receptor-independent neuronal injury that is inhibited by specific ASIC1a blockade and by ASIC1 gene knockout $[21,57]$. Intracerebroventricular injection of PcTx1 (ASIC1a blocker/inhibitor) in animal models of brain ischemia reduced the infarct volume by up to $60 \%$. Protection by an ASIC1a blockade has an efficacy time window of approximately 5 hours, and the protection persists for at least 7 days $[21,54]$.

Furthermore, an ASIC1 gene knockout leads to significant neuroprotection in mice, and the reduction of ASIC1a expression contributes to neuroprotection as elicited by ischemic preconditioning and postconditioning in rats $[21,58]$. Increasing ASIC1a surface expression, for example, through inhibition of ASIC1a internalization, exacerbates acidosis-induced neuronal injury [59]. In a model of global ischemia, the ASICs inhibitor amiloride, but not the NMDA receptor blocker memantine, reduced brain damage indicating that in some models of brain ischemia, ASICs may play a larger role than glutamatergic NMDA receptors in the mediation of neuronal injury [60]. The protective effect of ASICs inhibition is additive to that of NMDA receptor inhibition, thus indicating that they take place by different mechanisms [61].

After an ischemic insult, AMPA receptor plasticity exacerbates excitotoxic damage in the hippocampal region, particularly the increased expression of $\mathrm{Ca}^{2+}$ permeable GluA2-lacking AMPA receptors (CP-AMPAR), which may play a significant role in postischemic neuronal cell death. In hippocampal slice cultures exposed to oxygen-glucose deprivation and in hippocampal pyramidal neuron cultures exposed to acidosis, it was found that ASIC1a activity promotes the expression of CP-AMPAR and of anoxic longterm potentiation, but ASIC1a inhibition confers neuroprotection [62]. In contrast, an opposite effect indicating that the ASIC1a deletion increases CP-AMPAR expression in the nucleus accumbens of the ventral striatum was also reported [5]. This discrepancy may be because ASIC1a could differentially regulate the expression of CP-AMPAR in a specific tissue manner.

Other ischemia-associated factors, such as arachidonic acid and lactate, endogenous polyamines, large dynorphin, and nitric oxide, also exacerbate acidosis-mediated neuronal injury and ischemic damage [56, 63-65]. These factors may act by enhancing the ASIC current or slowing its desensitization. For example, spermine, which is an endogenous polyamine found at high concentrations in the brain, shifts the steady-state inactivation of ASICla and potentiates ischemia-induced injury in the brain during stroke [66], showing that steady-state desensitization is a critical factor that can affect the degree of acid-evoked neuronal damage through ASIC1.

Interestingly, three compounds, puerarin, sophocarpine, and ginsenoside-Rd (found in several traditional Chinese preparations), as well as the flavonoid quercetin, protect against damage caused by middle cerebral artery occlusion. These compounds were found to reduce the current 
amplitude of ASIC1a, increase channel desensitization, or decrease ASIC1a expression [67-69].

Altogether, these findings support the participation of ASICs in excitotoxic neuronal injury and suggest a new pathophysiological model for ischemic brain injury in which extracellular acidification produces an over activation of the ASIC current. Thus, ASICs constitute a new therapeutic target for the treatment of ischemia-induced neuronal damage.

2.5. Spinocerebellar Ataxia. Spinocerebellar ataxias (SCAs) are a group of autosomal dominant progressive neurodegenerative disorders that display complex clinical and genetic heterogeneity. Spinocerebellar type 1 ataxia (SCA1) primarily affects the brainstem, spinocerebellar tracts, and cerebellar Purkinje cells (PC). Patients with SCA1 develop progressive ataxia accompanied by bulbar and pyramidal symptoms [70]. Mutations of the ataxin-1 gene are responsible for the disease, and induction of the mutation in mice produces many of the clinical features observed in SCA1 patients. The exact mechanism of PC and of spinocerebellar tract cell loss remains unclear. Currently, there are no specific treatments for SCA1.

Excitingly, ataxin-1 transgenic mice induced in an ASIC1a knockout mouse background demonstrated that deletion of the ASIC1a gene suppresses the SCA1 disease phenotype, improving the motor deficit and decreasing PC degeneration. This shows that ASIC1a may be a mediator of SCA1 pathogenesis and that targeting ASIC1a could be a novel approach to treat SCA1 [71].

SCA3 ataxia (the most common one) results from a CAG-trinucleotide expansion in the coding region of the ATXN3 gene, leading to an expanded polyglutamine (polyQ) sequence within the Ataxin-3 protein. Using the fruit fly D. melanogaster as a model, it was demonstrated that downregulating the Nach gene (an ortholog of ASICs in the fly) mitigates SCA3 pathogenesis, indicating that ASICs may be involved in the pathophysiology of SCA3 [72].

2.6. Malignant Glioma. Malignant gliomas, the most common subtype of primary brain tumors, are aggressive, highly invasive, and neurologically destructive tumors that are considered to be among the deadliest of human cancers [73]. ASIC1a is extensively expressed in malignant glial cells. Amiloride- and PcTx1-sensitive cation currents in human glioblastoma are produced by mixed ASIC and ENaC components, including ASIC1 and ASIC2. Inhibition of ASIC1 conductance by PcTx1 and by the amiloride analog, benzamil, decreases the glioma growth rate and cell migration as well as arrests the cell cycle [74-78]. ASIC1a knockdown models show a significant inhibition of glioblastoma cell migration [77].

By contrast, increasing surface expression of the ASIC2 subunit suppressed the proliferation and migration of glioblastoma cells [75]. This last result suggests that the role of ASIC subunits in the pathophysiology of glial cancer is complex and that no straightforward intervention seems to be feasible; thus, further knowledge of the role of ASICs in neoplastic development is required to develop a translational use of ASIC blockers or enhancers in this pathology.

\section{ASICs in Inflammatory Processes and Pain}

The inflammatory process implies activation of immune cells and release of a cocktail of chemical mediator known as "inflammatory soup." The inflammatory reactions are selflimited by the elimination of the cause $[79,80]$. ASICs may be modulated by various components of the inflammatory soup, including NGF, 5-HT, and bradykinin, among others $[81,82]$. In addition, the natural polyamines agmatine and arcaine may activate the ASIC3 subunit (the concentration of polyamines can increase to up to $1 \mathrm{mM}$ in inflamed tissues) [83], while spermine enhances ASIC1a activity by slowing its inactivation and accelerating its recovery from desensitization [66]. Indeed, intraplantar injections of 2-guanidine-4-methylquinazoline (GMQ) in wild-type mice cause marked pain-related behaviors that are abolished in ASIC3 knockout mice [82].

It has been proposed that during inflammation, activation of ASICs is essential in nociception transduction and production of painful sensations. In sensory neurons, inflammation induces an increase in the ASIC current and its expression in the cell membrane, leading to an increase in neuronal excitability [82].

Microglia have been found to express ASICs, and stimulation of microglia with lipopolysaccharides leads to an increase in ASIC1 and ASIC2a expression as well as the release of inflammatory cytokines [84], demonstrating the role that ASICs play in neural sensitization during inflammatory processes.

3.1. Primary Inflammatory Pain. The role of ASICs in primary inflammatory pain has been investigated using various in vitro and in vivo experimental models [66, 85-88]. Most of the ASIC subtypes are expressed on nociceptive primary sensory neurons, where they seem to play a significant role in pain transduction $[3,89]$. Cutaneous pain produced by low $\mathrm{pH}$ solutions (at least over $\mathrm{pH}$ 6.0) is likely due to ASIC activation $[90,91]$.

Compounds inhibiting ASICs display an analgesic effect in animal models of pain [92], whereas those activating ASICs elicit pain behavior [85, 86, 88, 93], supporting a role for ASICs in the transduction of cutaneous pain.

During inflammation, the $\mathrm{pH}$ value of the local area is always lower than the physiological $\mathrm{pH}$, ranging from $\mathrm{pH}$ 5.5 to 7 [94]; this $\mathrm{pH}$ drop is sufficient to activate ASICs. Indeed, inflammation induces a marked increase of ASICs expression in primary sensory neurons, and nonsteroidal anti-inflammatory drugs (NSAIDs) attenuate the ASIC current [95]. Furthermore, in isolated dorsal root ganglion (DRG) neurons, a mixture of proinflammatory mediators, such as nerve growth factor, serotonin, interleukin-1, and bradykinin, increases the number of neurons expressing ASIC as well as their current density [82]. Bradykinin and serotonin act on ASICs through an indirect intracellular signaling pathway involving protein kinase C. Bradykinin activates bradykinin $\mathrm{B} 1$ and $\mathrm{B} 2 \mathrm{G}$ protein-coupled receptors (GPCR) [96], while serotonin acts on the GPCR 5- $\mathrm{HT}_{2}$ [97]. B1, B2, and $5-\mathrm{HT}_{2}$ receptors are constitutively expressed in sensory neurons, and their activation has been 
associated with inflammatory hyperalgesia. The binding of bradykinin and serotonin to their receptors induces phospholipase C (PLC) stimulation through heterotrimeric G proteins $\left(\mathrm{G}_{\mathrm{q} / 11}\right)[96,98,99]$. PLC cleaves phospholipid phosphatidylinositol 4,5-bisphosphate (PIP2) into diacyl glycerol (DAG) and inositol 1,4,5-trisphosphate (IP3). IP3 releases $\mathrm{Ca}^{2+}$ from the internal $\mathrm{Ca}^{2+}$ stores in the endoplasmic reticulum, and DAG activates PKC. ASICs have a PDZ-binding domain at their C-termini; its interaction with PDZcontaining proteins regulates surface expression and activity of ASICs [37, 99]. The protein C-kinase (PICK1) colocalizes with ASICs, interacting directly through the PDZ-binding domain [100]. Therefore, the PKC signaling pathway may be involved in the enhancement of the ASICs mediated by inflammatory mediators.

Serotonin also directly binds to the extracellular domain of ASIC3 to increase its current [101]. The enhancing action of serotonin occurs in the sustained component of the ASIC3 current, which is particularly important for its painmediating effect [102-104]. Interestingly, serotonin acts not only on ASIC3 homomeric channels but also on heteromeric channels composed of ASIC3-ASIC1a or ASIC3-ASIC1b subunits [101].

Other inflammatory stimuli, such as ATP, lactic acid, arachidonic acid, nitric oxide (NO), agmatine, and hypertonicity, are able to enhance the proton-induced ASIC current. ATP can increase the $\mathrm{pH}$ sensitivity of ASIC3, and it has been proposed that this phenomenon of "sensitization" involves a protein assembly of P2X purinergic receptor and ASICs [57, $63,85,105,106]$.

NO can potentiate the activity of ASICs in DRG neurons and Chinese hamster ovary $(\mathrm{CHO})$ cells expressing ASIC subunits; this potentiation is probably due to the oxidation of cysteine residues of the channels. Additionally, topical application of the NO donor glyceryl trinitrate significantly increased acid-evoked pain in human volunteers without affecting their heat or mechanical pain threshold [107]. In the central nervous system, ASIC potentiation by NO aggravates acid-induced cell death during mild or moderate acidosis [55].

Histamine and histamine agonists were shown to potentiate ASIC currents in transfected CHO cells, apparently by specifically binding to the acid pocket of ASIC1a subunits [108]. Our research group found that histamine also potentiates ASIC currents in DRG neurons isolated from the rat, thus contributing to hypersensitivity in inflammatory conditions.

The ASIC currents in rat DRG neurons are produced by ASIC1 and ASIC3 [85, 109, 110]. The anemone toxin APETx2, which blocks ASIC3-containing channels, has potent analgesic effects after local application in rodent cutaneous acidic and inflammatory pain $[111,112]$.

ASIC3 also participates in the maintenance of subacute primary hyperalgesia (an increased response to noxious stimuli at the site of injury) in the case of cutaneous inflammation [113]. ASIC3 knockout mice fail to develop secondary hyperalgesia (an increased response to noxious stimuli outside the site of injury) induced by either repetitive acid injections into muscle [114], muscle inflammation [114], or knee inflammation [115].
Intrathecal injection of the ASIC1a blocker PcTx1 attenuates acute pain responses as well as pain behaviors in chronic inflammatory and neuropathic models. This is probably due to activation of the encephalinergic system secondary to ASIC1a blockade, but the precise mechanism has not yet been defined [88]. Additionally, a recently identified blocker of ASIC1a from the venom of the black mamba (Dendroapsis polylepis) named mambalgin-1 attenuated a variety of pain behaviors when administered centrally [86].

Injection of coral snake toxin MitTx, a potent activator of ASIC1 into the skin of the hind paw of a mouse produces a nociceptive behavior that is missing in ASIC1a knockout mice [92]. Similarly, mambalgin-1 (the ASIC1 and ASIC2 blockers) administered via intraplantar injection in mice attenuates both acute thermal nociception and inflammatory hyperalgesia, an effect that is lost in ASIC1b knockdown [86]. Finally, two clinical studies successfully used amiloride or a nonsteroidal anti-inflammatory drug to inhibit acid-evoked pain in human skin $[91,92]$.

Additionally, the aminoglycosides streptomycin and neomycin, which were shown to inhibit proton-gated currents in rat DRG neurons and reduce their action potential response to an acidic stimulus, have a significant analgesic action when administered locally in a model of inflammatory pain $[87,116]$. Streptomycin also reduces the GMQ-induced nociceptive behavior, indicating that aminoglycoside antibiotics produce analgesia due in part to the inhibition of ASICs activation in sensory neurons [116].

Although diverse evidence attests to the role of ASICs in nociception, conflicting results from studies of knockout and transgenic mice exist. In acute pain paradigms, ASIC3-/- mice were hyperalgesic to high-intensity thermal, mechanical, and acid stimuli $[117,118]$. Similar results were found in transgenic mice overexpressing dominant-negative ASIC3 [119].

3.2. Migraine. Migraine is one of the most common neurological disorders and a chronic pain condition that is usually accompanied by a variety of symptoms, including aura, nausea, vomiting, photophobia, and phonophobia. Although the exact pathophysiology of migraine headaches is still partially unknown, activation of the meningeal sensory neurons is likely required $[120,121]$.

In $80 \%$ of trigeminal afferent neurons originating from meninges, ASIC-like currents can be evoked at $\mathrm{pH}$ 6.0, and over $50 \%$ are also responsive to $\mathrm{pH} 7.0$ [121]. In animal models of migraine where low $\mathrm{pH}$ stimuli (from 5 to 6.4) were applied directly to the dura mater of awake animals, the acidic $\mathrm{pH}$ produced headache-like behavior that was blocked by amiloride or APETx2 (pH 6.0) [122].

Cortical spreading depression (CSD) is a neuronal process that linked to migraine and consists of brief neuronal excitation followed by a longer-lasting depression of activity. A CSD event propagates across the cortex in a wave-like mode. CDS is thought to be linked to migraine with aura because during this phase, changes in vision, particularly the movement/expansion of geometric shapes or scintillating scotomas, occur and can be mapped as electrical changes in the visual cortex consistent with CSD propagation. Whether 
CSD participates in other phases of migraine is unclear [40, 123]. Amiloride and PcTx1 block CSD and inhibit trigeminal activation in migraine models in vivo [124]. Intriguingly, there was no effect of ASIC blockers against CSD evoked by high $\mathrm{K}^{+}$, suggesting that ASICs may not contribute to all types of CSD. In a small clinical study, amiloride reduced both the aura frequency and headache severity [124].

3.3. Gastrointestinal Pain. ASICs (ASIC1, ASIC2, and ASIC3) are expressed by the peripheral axons of vagal and spinal afferent neurons. Retrograde tracing studies indicate that $75 \%$ of the nodose ganglion neurons and $82 \%$ of the DRG neurons projecting to the rat stomach express ASIC3like immunoreactivity [125]. In mouse thoracolumbar DRGs, ASIC3 is expressed in 73\%, ASIC2 in 47\%, and ASIC1 in $30 \%$ of the neurons projecting to the mouse colon [126].

ASIC3 plays a major role in inflammatory hyperresponsiveness to gastric acid as it may occur in gastritis and peptic ulcer disease. Disruption of the ASIC3 gene abolished the effect of gastritis and enhanced gastric acid-evoked expression of c-Fos in the brainstem. Conversely, ASIC2 gene knockout does not alter inflammatory hyperresponsiveness but enhances the medullary c-Fos response to the gastric acid challenge of the stomach [127]. ASIC3-/- mice have markedly reduced visceral mechanosensitivity compared to control animals and ASIC1-/- or ASIC2-/- mice [128], thus indicating the significant role of ASIC3 in gastrointestinal nociception.

The nonselective ASICs blocker benzamil produces a partial attenuation of the mechanosensitivity of gastroesophageal afferents, but its effect is more significant in colonic afferents [128]. The differential role of ASIC3 in the upper and lower GI tract indicates that this channel may serve as a key target for modulating GI nociception.

It is worth noting that dietary intake and bacterial metabolism may generate high concentrations of polyamines in the gut that may potentiate at low concentrations or directly activate ASIC currents [129]. Noteworthy also, some intestinal parasites, such as Echinococcus granulosus, produce and release peptides that may inhibit ASIC currents [130], thus producing an antinociceptive action and also probably an action modulating the dendritic cell response activated by acid which requires ASICs activation [131] Thence, the ASIC inhibition may constitute a mechanism by which parasites mitigate the nociception and immune response from the host, facilitating parasite infestation.

3.4. Cardiac Pain. Cardiac afferent neurons express ASIC3 that are activated by mild acidification during ischemia $[132,133]$. The acid-gated currents from ASIC3-/- cardiac afferents match the properties of ASIC2a, and currents from ASIC2-/- cardiac afferents match the properties of ASIC3 [133], thus demonstrating that ASIC currents in myocardial afferents are due to ASIC3-ASIC2 heteromers. ASIC3 seems to be the sensor of myocardial acidity that triggers cardiac pain, thus constituting a potential pharmaceutical target for treating angina pectoris [133].

Regrettably, not all ASIC-blocking drugs are useful for treating cardiac pain during ischemic attacks; it has been shown that amiloride, although, reducing the peak ASIC current in cardiac sensory neurons, is also able to increase the sustained component [104], which is predominantly expressed in ASIC3 and important for the transduction of chemical stimuli and nociception (Figure 1(b)). In contrast, ligustrazine, a compound extracted from the roots of Ligusticum chuanxiong, attenuated ASIC currents in DRG neurons and in $\mathrm{CHO}$ cells transfected with ASIC cDNAs [134]. In a rat model of angina, ligustrazine and ASICs inhibitor A-317567 also reduced the cardiac ischemiainduced electrical dysfunction and infarct size. Thus, inhibition of ASICs by ligustrazine may explain the beneficial effects of the drug in patients with ischemic heart disease and angina [134].

3.5. Postoperatory Pain. Postoperative pain is a common clinical condition produced by multiple processes, including tissue damage, secondary inflammation, and nerve damage caused by tissue manipulation during surgery [135]. Pain can be acute or chronic and produces a series of physiological consequences, including activation of the "stress response," which broadly affects various tissues in patients [136].

In a rat model of postoperative pain, high levels of ASICtype currents $(\sim 77 \%)$ were found in sensory neurons innervating the hind paw muscles, with a high prevalence of ASIC3-like currents. Pharmacological inhibition of ASIC3 with APETx2, or in vivo knockdown of ASIC3 by interfering RNA, led to a significant reduction of postoperative spontaneous, thermal, and postural pain behavior. A single intraoperative application of APETx2 was an effective analgesic for 24 hours after surgery [111].

3.6. Muscular Pain. The role of ASICs in muscle pain has been studied in inflammatory and noninflammatory models $[137,138]$. In noninflammatory pain, an intramuscular acidic saline injection produces nociceptive behavior $[139,140]$. Intramuscular acid-induced pain was seen in ASIC1-/-, but not in ASIC3-/- mice, although ASIC1-/mice developed secondary mechanical hyperalgesia of the paw; however, this response was completely abolished in ASIC3-/- mice [114]. Similarly, blockade of ASICs with amiloride or with the ASIC3 antagonist APETx2 prevents the development of hyperalgesia $[112,140]$. ASICs inhibition 24 hours after a second intramuscular acid injection, at a time when hyperalgesia is well established, had no effect on muscle or cutaneous hyperalgesia. In patch clamp recordings from DRG neurons $24 \mathrm{~h}$ after the second acid injection, neurons show no changes in responsiveness to acidic $\mathrm{pH}$ stimuli, suggesting that long-lasting hyperalgesia is independent of ASICs activation [137].

In human subjects, infusion of an acidic buffer into the anterior tibialis muscle results in local pain at the injection zone and also produces a referred pain at the ankle; additionally, subjects report hyperalgesia to pressure pain at the site of infusion and at the ankle (secondary hyperalgesia) [141].

In adult mice, knockdown of ASIC3 in DRG innervating muscle with microRNA (miRNA) prevents the development of both paw and muscle hyperalgesia in mice with muscle 
inflammation [142]. Twenty-four hours after carrageenaninduced muscle inflammation in mice, the mRNA of ASIC2 and ASIC3 (but not ASIC1) in lumbar DRG neurons increases bilaterally [143]. Additionally, in DRG neurons that innervate muscle, there are enhanced ASIC-like currents under an acidic $\mathrm{pH}$ [139]. The study also shows that the nonselective ASIC inhibitor A-317567 can reverse both primary and secondary hyperalgesia.

Rescuing ASIC3 expression in primary afferent fibers that innervate muscle in ASIC3 knockout mice restores the mechanical hyperalgesia of the paw [115], whereas downregulation of ASIC3 in muscular sensory fibers in wild-type animals prevents the development of inflammatory hyperalgesia [142].

ASIC3 was involved in the transition from acute to chronic pain in a mouse model of fibromyalgia induced by intramuscular acid injections. Inhibition of ASIC3 with APETx2 abolished hyperalgesia at the time of the first acid injection and prevented the induction of chronic hyperalgesia by a subsequent acid injection (five days later). It was also shown that ASIC3-/- mice did not develop mechanical hyperalgesia after repeated acid injections [144, 145].

\section{Conclusion}

The etiology of neurodegenerative diseases is varied and probably multifactorial, but these diseases share common processes, such as accumulation of misfolded proteins or metabolic alterations leading to damage to specific neuronal populations as well as chronic inflammation; therefore, two seemingly distant processes, such as neurodegeneration and neuroinflammation, can be causally related and share one or more similar pharmacological targets [146].

Neurodegenerative disorders are associated with different processes such as neurovascular disintegration, defective blood-brain barrier function, and microvascular dysfunction [147]; these processes cause a decrease in brain flow that leads to a reduction in the oxygen and nutrient supply to the brain, in addition to causing a decrease in the extracellular $\mathrm{pH}$ that may lead to apoptosis [148], protein misfolding $[149,150]$, excitotoxicity $[151,152]$, and neurodegeneration $[153,154]$. In this context, several noninvasive methods have been developed to measure $\mathrm{pH}$ with high spatial and temporal resolution in both clinical and preclinical studies of neurodegenerative disorders. In fact, it has been suggested to use $\mathrm{pH}$ measurements by means of magnetic resonance spectroscopy as a potential biomarker of neurodegeneration [155-157].

Several studies have shown that ASICs play a significant role in inflammatory processes, as well as in neurodegenerative diseases, such as Parkinson's disease, multiple sclerosis, and cerebrospinal ataxia, among others. The use of several techniques, including electrophysiology, molecular biology, genetics, biochemistry, and in silico analysis, has produced a large amount of knowledge indicating the salient role of ASICs in the physiology and pathophysiology of inflammatory and degenerative diseases.

Because the ASICs show a significant desensitization to $\mathrm{pH}$ stimuli, they cannot remain activated during long-term
$\mathrm{pH}$ changes, or in any case, it remains a sustained component of the current, but its magnitude is low and in the long term must probably completely cancelled; thus explaining why sustained acidosis is necessary but not sufficient to damage the SNC. So, as in many other physiological and pathological processes, a combination of factors is essential for its development. Thence, ASICs activation seems necessary but not a sufficient cause to produce neurodegeneration. The production of ASICs modulator agents such as sulfhydryl-containing molecules dithiothreitol (DTT) and glutathione [158], among others, may shift the pH of ASICs toward more neutral $\mathrm{pH}$ and slow channel desensitization, thus significantly increasing the inward sodium current passing through the ASICs and contributing to enhance the acidinduced tissue damage.

Inflammation is a necessary and evolutionarily conserved response to harmful stimuli that produce tissue damage or degeneration as well as to various pathogens that invade the host. The inflammatory process leads to the release of numerous mediators, including purines, prostaglandins, bradykinins, histamine, serotonin, nerve growth factor (NGF), cytokines, and protons (among others) [159]. The low $\mathrm{pH}$ levels found in inflamed tissue led to the hypothesis that local acidosis may contribute to pain and hyperalgesia. ASICs are involved in nociceptive transduction and DRG neuronal sensitization, thus constituting a new, potentially significant target for the treatment of pain and hyperalgesia in diseases associated with inflammation.

Pharmacologically, the substances that modulate ASICs have grown significantly and now include many synthetic inhibitors as well as various organic molecules obtained from animals, vegetables, and even endogenous ones [160]. The increase in pharmacological, physiological, and pathophysiological processes that are mediated by ASICs opens new perspectives for the synthesis of pharmacological tools that may contribute to the armamentarium against neuroinflammatory diseases, some of the most challenging health problems faced in modern times. Furthermore, there is a trend to search for multitarget molecules that may reach an efficient neuroprotective effect [161].

\section{Conflicts of Interest}

The authors declare that they have no conflicts of interest.

\section{Acknowledgments}

This work is part of the fulfillment of the requirements for the Doctorate in Physiological Sciences of Audrey OrtegaRamírez. This work was financed by a grant from the Mexican Space Agency (AEM) and the National Council of Science and Technology ((CONACyT) Grant no. 275058 to Rosario Vega and CONACyT Grant no. 167059 to Enrique Soto; PROFOCIE 2016 and VIEP-BUAP 2016 grants to Rosario Vega and Enrique Soto). Audrey Ortega-Ramírez was supported by a CONACyT fellowship reference 226512. The authors wish to thank Dr. Francisco Mercado for his critical reading of the manuscript. 


\section{References}

[1] M. Chesler, "Regulation and modulation of $\mathrm{pH}$ in the brain," Physiological Reviews, vol. 83, no. 4, pp. 1183-1222, 2003.

[2] S. D. McAlear and M. O. Bevensee, " $\mathrm{pH}$ regulation in nonneuronal brain cells and interstitial fluid," Advances in Molecular and Cell Biology, vol. 31, pp. 707-745, 2004.

[3] D. A. de la Rosa, P. Zhang, D. Shao, F. White, and C. M. Canessa, "Functional implications of the localization and activity of acid-sensitive channels in rat peripheral nervous system," Proceedings of the National Academy of Sciences, vol. 99, no. 4, pp. 2326-2331, 2002.

[4] M. Obara, M. Szeliga, and J. Albercht, "Regulation of $\mathrm{pH}$ in the mammalian central nervous system under normal and pathological conditions: facts and hypotheses," Neurochemistry International, vol. 52, no. 6, pp. 905-919, 2008.

[5] C. J. Kreple, Y. Lu, R. J. Taugher et al., "Acid-sensing ion channels contribute to synaptic transmission and inhibit cocaine-evoked plasticity," Nature Neuroscience, vol. 17, no. 8, pp. 1083-1091, 2014.

[6] J. Du, L. R. Reznikov, M. P. Price et al., "Protons are a neurotransmitter that regulates synaptic plasticity in the lateral amygdala," Proceedings of the National Academy of Science of the United States of America, vol. 111, no. 24, 2014.

[7] A. A. Beg, G. G. Ernstrom, P. Nix, M. W. Davis, and E. M. Jorgensen, "Protons act as a transmitter for muscle contraction in C. elegans," Cell, vol. 132, no. 1, pp. 149-160, 2008.

[8] M. Ettaiche, E. Deval, M. Cougnon, M. Lazdunski, and N. Voilley, "Silencing acid-sensing ion channel 1a alters conemediated retinal function," Journal of Neuroscience, vol. 26, no. 21, pp. 5800-5809, 2006.

[9] F. Mercado, A. López, D. Acuna, R. Vega, and E. Soto, "Acid-sensing ion channels in the rat vestibular endorgans and ganglia," Journal of Neurophysiology, vol. 96, no. 3, pp. 1615-1624, 2006.

[10] C. C. Cheng and C. W. Wong, "Neurosensory mechanotransduction through acid-sensing ion channels," Journal of Cellular and Molecular Medicine, vol. 17, no. 3, pp. 337-349, 2013.

[11] A. González-Garrido, R. Vega, F. Mercado, I. A. López, and E. Soto, "Acid-sensing ion channels expression, identity and role in the excitability of the cochlear afferent neurons," Frontiers in Cellular Neuroscience, vol. 9, p. 483, 2015.

[12] C. González-Inchauspe, F. J. Urbano, M. N. Di Guilmi, and O. D. Uchitel, "Acid sensing ion channels activated by evoked released protons modulate synaptic transmission at the mouse calyx of Held synapse," Journal of Neuroscience, vol. 37, no. 10, pp. 2589-2599, 2017.

[13] R. Waldmann, G. Champigny, F. Bassilana, C. Heurteaux, and M. Lazdunski, "A proton-gated cation channel involved in acid-sensing," Nature, vol. 386, no. 6621, pp. 173-177, 1997.

[14] J. Jasti, H. Furukawa, E. B. González, and E. Gouaux, "Structure of acid-sensing ion channel 1 at 1.9 A resolution and low pH," Nature, vol. 449, no. 7160, pp. 316-323, 2007.

[15] E. B. González, T. Kawate, and E. Gouaux, "Pore architecture and ion sites in acid-sensing ion channels and P2X receptors," Nature, vol. 460, no. 7255, pp. 599-604, 2009.

[16] E. L. Bässler, T. J. Ngo-Anh, H. S. Geisler, J. P. Ruppersberg, and S. Gründer, "Molecular and functional characterization of acid-sensing ion channel (ASIC) 1b," Journal of Biological Chemistry, vol. 276, no. 36, pp. 33782-33787, 2001.
[17] M. Hesselager, D. B. Timmermann, and P. K. Ahring, " $\mathrm{pH}$ dependency and desensitization kinetics of heterologously expressed combinations of acid sensing ion channel subunits," Journal of Biological Chemistry, vol. 279, no. 12, pp. 11006-11015, 2004.

[18] S. H. Lin, Y. C. Chien, W. W. Chiang, Y. Z. Liu, C. C. Lien, and C. C. Chen, "Genetic mapping of ASIC4 and contrasting phenotype to ASIC1a in modulating innate fear and anxiety," European Journal of Neuroscience, vol. 41, no. 12, pp. 15531568, 2015.

[19] N. Boiko, V. Kucher, B. Wang, and J. D. Stockand, "Restrictive expression of acid-sensing ion channel 5 (Asic5) in unipolar brush cells of the vestibulocerebellum," PLoS One, vol. 9, no. 3, article e91326, 2014.

[20] M. X. Van Bemmelen, D. Huser, I. Gautschi, and L. Schild, "The human acid-sensing ion channel ASICla: evidence for a homotetrameric assembly state at the cell surface," PLoS One, vol. 10, no. 8, article e0135191, 2015.

[21] Z. G. Xiong, X. M. Zhu, X. P. Chu et al., "Neuroprotection in ischemia: blocking calcium-permeable acid-sensing ion channels," Cell, vol. 118, no. 6, pp. 687-698, 2004.

[22] O. Yermolaieva, A. S. Leonard, M. K. Schnizler, F. M. Abboud, and M. J. Welsh, "Extracellular acidosis increases neuronal cell calcium by activating acid-sensing ion channel 1a," Proceedings of the National Academy of Science of the United States of America, vol. 101, no. 17, pp. 6752-6757, 2004.

[23] T. W. Sherwood, K. G. Lee, M. G. Gormley, and C. C. Askwith, "Heteromeric acid-sensing ion channels (ASICs) composed of ASIC2b and ASIC1a display novel channel properties and contribute to acidosis-induced neuronal death," Journal of Neuroscience, vol. 31, no. 26, pp. 9723-9734, 2011.

[24] C. Canessa, "Acid sensing ion channels," in In Handbook of Ion Channels, pp. 383-394, CRC Press, Boca Ratón, FL, USA, 2015.

[25] V. C. Vralsted, M. P. Price, J. Du et al., "Expressing acidsensing ion channel 3 in the brain alters acid-evoked currents and impairs fear conditioning," Genes, Brain and Behavior, vol. 10, no. 4, pp. 444-450, 2011.

[26] S. Gründer and M. Pusch, "Biophysical properties of acid-sensing ion channels (ASICs)," Neuropharmacology, vol. 94, pp. 9-18, 2015.

[27] E. Babini, M. Paukert, H. S. Geisler, and S. Grunder, "Alternative splicing and interaction with di- and polyvalent cations control the dynamic range of acid sensing ion channel 1 (ASIC1)," Journal of Biological Chemistry, vol. 277, no. 44, pp. 41597-41603, 2002.

[28] C. J. Benson, J. A. Wemmie, M. P. Price, J. M. Henss, M. J. Welsh, and P. M. Snyder, "Heteromultimers of DEG/ENaC subunits form $\mathrm{H}^{+}$-gated channels in mouse sensory neurons," Proceedings of the National Academy of Sciences, vol. 99, no. 4, pp. 2338-2343, 2002.

[29] A. Delaunay, X. Gasull, M. Salinas et al., "Human ASIC3 channel dynamically adapts its activity to sense the extracellular $\mathrm{pH}$ in both acidic and alkaline directions," Proceedings of the National Academy of Sciences, vol. 109, no. 32, pp. 13124-13129, 2012.

[30] M. M. Goldenberg, "Multiple sclerosis review," Pharmacy and Therapeutics, vol. 37, no. 3, pp. 175-184, 2012.

[31] M. A. Friese, M. J. Craner, R. Etzensperger et al., "Acidsensing ion channel-1 contributes to axonal degeneration 
in autoimmune inflammation of the central nervous system," Nature Medicine, vol. 13, no. 12, pp. 14831489, 2007.

[32] S. Vergo, M. J. Craner, R. Etzensperger et al., "Acid-sensing ion channel 1 is involved in both axonal injury and demyelination in multiple sclerosis and its animal model," Brain, vol. 134, Part 2, pp. 571-584, 2011.

[33] T. Arun, V. Tomassini, E. Sbardella et al., "Targeting ASIC1 in primary progressive multiple sclerosis: evidence of neuroprotection with amiloride," Brain, vol. 136, Part 1, pp. 106-115, 2013.

[34] J. M. Beitz, "Parkinson's disease: a review," Frontiers in Bioscience, vol. 6, pp. 65-74, 2014.

[35] V. I. Pidoplichko and J. A. Dani, "Acid-sensitive ionic channels in midbrain dopamine neurons are sensitive to ammonium, which may contribute to hyperammonemia damage," Proceedings of the National Academy of Science, vol. 103, no. 30, pp. 11376-11380, 2006.

[36] R. L. Arias, M. L. A. Sung, D. Vasylyev et al., "Amiloride is neuroprotective in an MPTP model of Parkinson's disease," Neurobiology of Disease, vol. 31, no. 3, pp. 334-341, 2008.

[37] M. Joch, A. R. Ase, C. X. Chen et al., "Parkin-mediated monoubiquitination of the PDZ protein PICK1 regulates the activity of acid-sensing ion channels," Molecular Biology of the Cell, vol. 18, no. 8, pp. 3105-3118, 2007.

[38] X. Sun, Y. B. Cao, L. F. Hu et al., "ASICs mediate the modulatory effect by paeoniflorin on alpha-synuclein autophagic degradation," Brain Research, vol. 1396, pp. 77-87, 2011.

[39] R. P. Simon, N. Benowitz, R. Hedlund, and J. Copeland, "Influence of the blood-brain $\mathrm{pH}$ gradient on brain phenobarbital uptake during status epilepticus," Journal of Pharmacology and Experimental Therapeutics, vol. 234, no. 3, pp. 830-835, 1985.

[40] G. G. Somjen, "Acidification of interstitial fluid in hippocampal formation caused by seizures and by spreading depression," Brain Research, vol. 311, no. 1, pp. 186-188, 1984.

[41] M. Chesler and K. Kaila, "Modulation of $\mathrm{pH}$ by neuronal activity," Trends in Neurosciences, vol. 15, no. 15, pp. 396402, 1992.

[42] G. Biagini, K. Babinski, M. Avoli, M. Marcinkiewicz, and P. Séguéla, "Regional and subunit-specific downregulation of acid-sensing ion channels in the pilocarpine model of epilepsy," Neurobiology of Disease, vol. 8, no. 1, pp. 45-58, 2001.

[43] A. Ali, F. J. Ahmad, K. K. Pillai, and D. Vohora, "Evidence of the antiepileptic potential of amiloride with neuropharmacological benefits in rodent models of epilepsy and behavior," Epilepsy and Behavior, vol. 5, no. 3, pp. 322-328, 2004.

[44] A. Ali, K. P. Pillai, F. J. Ahmad, Y. Dua, and D. Vohora, "Anticonvulsant effect of amiloride in pentetrazole-induced status epilepticus in mice," Pharmacological Reports, vol. 58, no. 2, pp. 242-245, 2006.

[45] P. N'Gouemo, "Amiloride delays the onset of pilocarpineinduced seizures in rats," Brain Research, vol. 1222, pp. 230-232, 2008.

[46] A. E. Ziemann, M. K. Schnizler, G. W. Albert et al., "Seizure termination by acidosis depends on ASIC1a," Nature Neuroscience, vol. 11, no. 7, pp. 816-822, 2008.

[47] Q. Cao, W. Wang, J. Gu et al., "Elevated expression of acid-sensing ion channel 3 inhibits epilepsy via activation of interneurons," Molecular Neurobiology, vol. 53, no. 1, pp. 485-498, 2014.
[48] H. Wu, C. Wang, B. Liu et al., "Altered expression pattern of acid-sensing ion channel isoforms in piriform cortex after seizures," Molecular Neurobiology, vol. 53, no. 3, pp. 17821793, 2015.

[49] T. Leng, Y. Shi, Z. G. Xiong, and D. Sun, "Proton-sensitive cation channels and ion exchangers in ischemic brain injury: new therapeutic targets for stroke?" Progress in Neurobiology, vol. 115, pp. 189-209, 2014.

[50] B. K. Siesjö, "Pathophysiology and treatment of focal cerebral ischemia: part I: pathophysiology," Journal of Neurosurgery, vol. 77, no. 2, pp. 169-184, 1992.

[51] M. Nedergaard, R. P. Kraig, J. Tanabe, and W. A. Pulsinelli, "Dynamics of interstitial and intracellular $\mathrm{pH}$ in evolving brain infarct," American Journal of Physiology-Regulatory, Integrative and Comparative Physiology, vol. 260, no. 3, Part 2, pp. R581-R588, 1991.

[52] A. J. Hansen and C. E. Olsen, "Brain extracellular space during spreading depression and ischemia," Acta Physiologica, vol. 108 , no. 4, pp. 355-365, 1980.

[53] Y. Mari, C. Katnik, and J. Cuevas, "ASIC1a channels are activated by endogenous protons during ischemia and contribute to synergistic potentiation of intracellular $\mathrm{Ca}^{2+}$ overload during ischemia and acidosis," Cell Calcium, vol. 48, no. 1, pp. 70-82, 2010.

[54] G. Pignataro, R. P. Simon, and Z. G. Xiong, "Prolonged activation of ASICla and the time window for neuroprotection in cerebral ischaemia," Brain, vol. 130, Part 1, pp. 151-158, 2007.

[55] S. K. Jetti, S. M. Swain, S. Majumder, S. Chatterjee, V. Poornima, and A. K. Bera, "Evaluation of the role of nitric oxide in acid sensing ion channel mediated cell death," Nitric Oxide, vol. 22, no. 3, pp. 213-219, 2010.

[56] J. Gao, B. Duan, D. G. Wang et al., "Coupling between NMDA receptor and acid-sensing ion channel contributes to ischemic neuronal death," Neuron, vol. 48, no. 4, pp. 635-646, 2005.

[57] M. Li, K. Inoue, D. Branigan et al., "Acid-sensing ion channels in acidosis-induced injury of human brain neurons," Journal of Cerebral Blood Flow and Metabolism, vol. 30, no. 6, pp. 1247-1260, 2010.

[58] G. Pignataro, O. Cuomo, E. Esposito, R. Sirabella, G. Di Renzo, and L. Annunziato, "ASIC1a contributes to neuroprotection elicited by ischemic preconditioning and postconditioning," International Journal of Physiology, Pathophysiology and Pharmacology, vol. 3, no. 1, pp. 18, 2011.

[59] W. Z. Zeng, D. S. Liu, B. Duan et al., "Molecular mechanism of constitutive endocytosis of acid-sensing ion channel 1a and its protective function in acidosis-induced neuronal death," The Journal of Neuroscience, vol. 33, no. 16, pp. 7066-7078, 2013.

[60] K. K. Tai and D. D. Truong, "Amiloride but not memantine reduces neurodegeneration, seizures and myoclonic jerks in rats with cardiac arrest-induced global cerebral hypoxia and reperfusion," PloS One, vol. 8, no. 4, article e60309, 2013.

[61] V. Mishra, R. Verma, N. Singh, and R. Raghubir, "The neuroprotective effects of NMDAR antagonist, ifenprodil and ASIC1a inhibitor, flurbiprofen on postischemic cerebral injury," Brain Research, vol. 1389, pp. 152-160, 2011.

[62] P. Quintana, D. Soto, O. Poirot et al., “Acid-sensing ion channel 1a drives AMPA receptor plasticity following ischaemia 
and acidosis in hippocampal CA1 neurons," The Journal of Physiology, vol. 593, no. 19, pp. 4373-4386, 2015.

[63] D. C. Immke and E. W. McCleskey, "Lactate enhances the acid-sensing $\mathrm{Na}^{+}$channel on ischemia-sensing neurons," Nature Neuroscience, vol. 4, no. 9, pp. 869-870, 2001.

[64] N. J. Allen and D. Attwell, "Modulation of ASIC channels in rat cerebellar Purkinje neurons by ischaemia-related signals," The Journal of Physiology, vol. 543, Part 2, pp. 521529, 2002.

[65] T. W. Sherwood and C. C. Askwith, "Dynorphin opioid peptides enhance acid sensing ion channel la activity and acidosis-induced neuronal death," Journal of Neuroscience, vol. 29, no. 45, pp. 14371-14380, 2009.

[66] B. Duan, Y. Z. Wang, T. Yang et al., "Extracellular spermine exacerbates ischemic neuronal injury through sensitization of ASIC1a channels to extracellular acidosis," Journal of Neuroscience, vol. 31, no. 6, pp. 2101-2112, 2011.

[67] L. Gu, Y. Yang, Y. Sun, and X. Zheng, "Puerarin inhibits acid-sensing ion channels and protects against neuron death induced by acidosis," Planta Medica, vol. 76, no. 6, pp. 583-588, 2010.

[68] Y. Zhang, L. Zhou, L. Zhang, J. Bai, M. Shi, and G. Zhao, "Ginsenoside-Rd attenuates TRPM7 and ASIC1a but promotes ASIC2a expression in rats after focal cerebral ischemia," Neurological Sciences, vol. 33, no. 5, pp. 1125-1131, 2012.

[69] A. K. Pandey, S. Verma, P. Bhattacharya, S. Paul, A. Mishra, and R. Patnaik, "An in-silico strategy to explore neuroprotection by quercetin in cerebral ischemia: a novel hypothesis based on inhibition of matrix metalloproteinase (MMPs) and acid sensing ion channel 1a (ASIC1a)," Medical Hypotheses, vol. 79, no. 1, pp. 76-81, 2012.

[70] C. Zühlke, A. Dalski, Y. Hellenbroich, S. Bubel, E. Schwinger, and K. Bürk, "Spinocerebellar ataxia type 1 (SCA1): phenotype-genotype correlation studies in intermediate alleles," European journal of human genetics: E.J.H.G., vol. 10, no. 3, pp. 204-209, 2002.

[71] P. J. Vig, S. M. Hearst, Q. Shao, and M. E. Lopez, "Knockdown of acid-sensing ion channel 1a (ASIC1a) suppresses disease phenotype in SCA1 mouse model," Cerebellum, vol. 13, no. 4, pp. 479-490, 2014.

[72] L. McGurk and N. M. Bonini, "Protein interacting with C kinase (PICK1) is a suppressor of spinocerebellar ataxia 3-associated neurodegeneration in Drosophila," Human Molecular Genetics, vol. 21, no. 1, pp. 76-84, 2012.

[73] E. A. Maher, F. B. Furnari, R. M. Bachoo et al., "Malignant glioma: genetics and biology of a grave matter," Genes \& Development, vol. 15, no. 11, pp. 1311-1333, 2001.

[74] B. K. Berdiev, J. Xia, L. A. McLean et al., "Acid-sensing ion channels in malignant gliomas," Journal of Biological Chemistry, vol. 278, no. 17, pp. 15023-15034, 2003.

[75] W. H. Vila-Carriles, G. G. Kovacs, B. Jovov et al., "Surface expression of ASIC2 inhibits the amiloride-sensitive current and migration of glioma cells," Journal of Biological Chemistry, vol. 281, no. 28, pp. 19220-19232, 2006.

[76] J. K. Bubien, H. L. Ji, G. Y. Gillespie et al., "Cation selectivity and inhibition of malignant glioma $\mathrm{Na}^{+}$channels by Psalmotoxin 1," American Journal of Physiology-Cell Physiology, vol. 287, no. 5, pp. C1282-C1291, 2004.

[77] N. Kapoor, R. Bartoszewski, Y. Qadri et al., "Knockdown of ASIC1 and epithelial sodium channel subunits inhibits glioblastoma whole cell current and cell migration," Journal of Biological Chemistry, vol. 284, no. 36, pp. 24526-24541, 2009.

[78] A. K. Rooj, C. M. McNicholas, R. Bartoszewski, Z. Bebok, D. J. Benos, and C. M. Fuller, "Glioma-specific cation conductance regulates migration and cell cycle progression," Journal of Biological Chemistry, vol. 287, no. 6, pp. 40534065, 2012.

[79] M. Ringkamp, S. N. Raja, J. N. Campbell, and R. A. Meyer, "Peripheral mechanisms of cutaneous nociception," in Wall and Melzack's Textbook of Pain, pp. 1-30, Elsevier Saunders, Philadelphia, PA, USA, 2003.

[80] G. Schett, "Review: immune cells and mediators of inflammatory arthritis," Autoimmunity, vol. 41, no. 3, pp. 224-229, 2008.

[81] J. Mamet, A. Baron, M. Lazdunski, and N. Voilley, "Proinflammatory mediators, stimulators of sensory neuron excitability via the expression of acid-sensing ion channels," Journal of Neuroscience, vol. 22, no. 24, pp. 10662-10670, 2002.

[82] Y. Yu, Z. Chen, W. G. Li et al., "A nonproton ligand sensor in the acid-sensing ion channel," Neuron, vol. 68, no. 1, pp. 61-72, 2010.

[83] W. G. Li, Y. Yu, Z. D. Zhang, H. Cao, and T. L. Xu, “ASIC3 channels integrate agmatine and multiple inflammatory signals through the nonproton ligand sensing domain," Molecular Pain, vol. 6, no. 1, p. 88, 2010.

[84] X. W. Yu, Z. L. Hu, M. Ni et al., “Acid-sensing ion channels promote the inflammation and migration of cultured rat microglia," Glia, vol. 63, no. 3, pp. 483-496, 2015.

[85] E. Deval, J. Noel, N. Lay et al., "ASIC3, a sensor of acidic and primary inflammatory pain," The EMBO Journal, vol. 27, no. 22, pp. 3047-3055, 2008.

[86] S. Diochot, A. Baron, M. Salinas et al., "Black mamba venom peptides target acid-sensing ion channels to abolish pain," Nature, vol. 490, no. 7421, pp. 552-555, 2012.

[87] A. Garza, O. López-Ramírez, R. Vega, and E. Soto, "The aminoglycosides modulate the acid-sensing ionic channel currents in dorsal root ganglion neurons from the rat," Journal of Pharmacology and Experimental Therapeutics, vol. 332, no. 2, pp. 489-499, 2010.

[88] M. Mazzuca, C. Heurteaux, A. Alloui et al., "A tarantula peptide against pain via ASIC1a channels and opioid mechanisms," Nature Neuroscience, vol. 10, no. 8, pp. 943-945, 2007.

[89] J. A. Wemmie, R. J. Taugher, and C. J. Kreple, “Acid-sensing ion channels in pain and disease," Nature Reviews in Neuroscience, vol. 14, no. 7, pp. 461-471, 2013.

[90] N. G. Jones, R. Slater, H. Cardiou, P. McNaughton, and S. B. McMahon, "Acid-induced pain and its modulation in humans," Journal of Neuroscience, vol. 24, no. 48, pp. 10974-10979, 2004.

[91] S. Ugawa, T. Ueda, Y. Ishida, M. Nishigaki, Y. Shibata, and S. Shimada, "Amiloride-blockable acid-sensing ion channels are leading acid sensors expressed in human nociceptors," The Journal of Clinical Investigation, vol. 110, no. 8, pp. 1185-1190, 2002.

[92] C. J. Bohlen, A. T. Chesler, R. Sharif-Naeini et al., "A heteromeric Texas coral snake toxin targets acid-sensing ion channels to produce pain," Nature, vol. 479, no. 7373, pp. 410-414, 2011. 
[93] G. R. Dube, S. G. Lehto, N. M. Breese et al., "Electrophysiological and in vivo characterization of A-317567, a novel blocker of acid sensing ion channels," Pain, vol. 117, no. 12, pp. 88-96, 2005.

[94] A. Lardner, "The effects of extracellular $\mathrm{pH}$ on immune function," Journal of Leukocyte Biology, vol. 69, no. 4, pp. 522-530, 2001.

[95] N. A. Dorofeeva, O. I. Barygin, A. Staruschenko, K. V. Bolshakov, and L. G. Magazanik, "Mechanisms of nonsteroid anti-inflammatory drugs action on ASICs expressed in hippocampal interneurons," Journal of Neurochemistry, vol. 106, no. 1, pp. 429-441, 2008.

[96] G. N. Prado, L. Taylor, X. Zhou, D. Ricupero, D. F. Mierke, and P. Polgar, "Mechanisms regulating the expression, self-maintenance, and signaling-function of the bradykinin B2 and B1 receptors," Journal of Cellular Physiology, vol. 193, no. 3, pp. 275-286, 2002.

[97] E. Sanders-Bush, H. Fentres, and L. Hazelwood, "Serotonin 5-ht2 receptors: molecular and genomic diversity," Molecular Interventions, vol. 3, no. 6, pp. 319-330, 2003.

[98] M. Sasaki, H. Obata, K. Kawahara, S. Saito, and F. Goto, "Peripheral 5-HT 2A receptor antagonism attenuates primary thermal hyperalgesia and secondary mechanical allodynia after thermal injury in rats," Pain, vol. 122, no. 1-2, pp. 130-136, 2006.

[99] E. Deval, M. Salinas, A. Baron, E. Lingueglia, and M. Lazdunski, "ASIC2b-dependent regulation of ASIC3, an essential acid-sensing ion channel subunit in sensory neurons via the partner protein PICK-1," Journal of Biological Chemistry, vol. 279, no. 19, pp. 19531-19539, 2004.

[100] A. Duggan, J. Garcia-Anoveros, and D. P. Corey, “The PDZ domain protein PICK1 and the sodium channels $\mathrm{BNaC1}$ interact and localize at mechanosensory terminals of dorsal root ganglion neurons and dendrites of central neurons," Journal of Biological Chemistry, vol. 277, no. 7, pp. 52035208, 2006.

[101] X. Wang, W. G. Li, Y. Yu et al., "Serotonin facilitates peripheral pain sensitivity in a manner that depends on the nonproton ligand sensing domain of ASIC3 channel," Journal of Neuroscience, vol. 33, no. 10, pp. 4265-4279, 2013.

[102] E. Deval, A. Baron, E. Lingueglia, H. Mazarguil, J. M. Zajac, and M. Lazdunski, "Effects of neuropeptide SF and related peptides on acid sensing ion channel 3 and sensory neuron excitability," Neuropharmacology, vol. 44, no. 5, pp. 662671, 2003.

[103] M. Salinas, M. Lazdunski, and E. Lingueglia, "Structural elements for the generation of sustained currents by the acid pain sensor ASIC3," Journal of Biological Chemistry, vol. 284, no. 46, pp. 31851-31859, 2009.

[104] J. Yagi, H. N. Wenk, L. A. Naves, and E. W. McCleskey, "Sustained currents through ASIC3 ion channels at the modest $\mathrm{pH}$ changes that occur during myocardial ischemia," Circulation Research, vol. 99, no. 5, pp. 501-509, 2006.

[105] W. T. Birdsong, L. Fierro, F. G. Williams et al., "Sensing muscle ischemia: coincident detection of acid and ATP via interplay of two ion channels," Neuron, vol. 68, no. 4, pp. 739-749, 2010.

[106] E. S. Smith, H. Cadiou, and P. A. McNaughton, “Arachidonic acid potentiates acid sensing ion channels in rat sensory neurons by a direct action," Neuroscience, vol. 145, no. 2, pp. 686-698, 2007.
[107] H. Cadiou, M. Studer, N. G. Jones et al., "Modulation of acid-sensing ion channel activity by nitric oxide," Journal of Neuroscience, vol. 27, no. 48, pp. 13251-13260, 2007.

[108] V. Y. Shteinikov, A. S. Korosteleva, T. B. Tikhonova, N. N. Potapieva, and D. B. Tikhonov, "Ligands of histamine receptors modulate acid-sensing ion channels," Biochemical and Biophysical Research Communications, vol. 490, no. 4, pp. 1314-1318, 2017.

[109] E. Deval, J. Noel, X. Gasull et al., "Acid-sensing ion channels in postoperative pain," Journal of Neuroscience, vol. 31, no. 16, pp. 6059-6066, 2011.

[110] O. Poirot, T. Berta, I. Decosterd, and S. Kellenberger, "Distinct ASIC currents are expressed in rat putative nociceptors and are modulated by nerve injury," The Journal of Physiology, vol. 576, no. 1, pp. 215-234, 2006.

[111] J. Karczewski, R. H. Spencer, V. M. Garsky et al., "Reversal of acid-induced and inflammatory pain by the selective ASIC3 inhibitor, APETx2," British Journal of Pharmacology, vol. 161, no. 14, pp. 950-960, 2010.

[112] Y. T. Yen, P. H. Tu, C. J. Chen, Y. W. Lin, S. T. Hsieh, and C. C. Chen, "Role of acid sensing ion channel 3 in sub-acutephase inflammation,” Molecular Pain, vol. 5, no. 1, p. 1, 2009.

[113] K. A. Sluka, M. P. Price, N. M. Breese, C. L. Stucky, J. A. Wemmie, and M. J. Welsh, "Chronic hyperalgesia induced by repeated acid injections in muscle is abolished by the loss of ASIC3, but not ASIC1," Pain, vol. 106, no. 3, pp. 229-239, 2003.

[114] K. A. Sluka, R. Radhakrishnan, C. J. Benson et al., "ASIC3 in muscle mediates mechanical, but not heat, hyperalgesia associated with muscle inflammation," Pain, vol. 129, no. 1-2, pp. 102-112, 2007.

[115] M. Ikeuchi, S. J. Kolker, L. A. Burnes, R. Y. Walder, and K. A. Sluka, "Role of ASIC3 in the primary and secondary hyperalgesia produced by joint inflammation in mice," Pain, vol. 137, no. 3, pp. 662-669, 2008.

[116] F. Mercado, A. Almanza, K. Simón-Arceo et al., "Inhibition of peripheral nociceptors by aminoglycosides produces analgesia in inflammatory pain models in the rat," Inflammation, vol. 38, no. 2, pp. 649-657, 2015.

[117] C. C. Chen, A. Zimmer, and W. H. Sun, "A role for ASIC3 in the modulation of high-intensity pain stimuli," Proceedings of the National Academy of Sciences, vol. 99, no. 13, pp. 8992$8997,2002$.

[118] A. A. Staniland and S. B. McMahon, "Mice lacking acidsensing ion channels (ASIC) 1 or 2, but not ASIC3, show increased pain behaviour in the formalin test," European Journal of Pain, vol. 13, no. 6, pp. 554-563, 2009.

[119] J. S. Mogil, N. M. Breese, and M. Witty, "Transgenic expression of a dominant-negative ASIC3 subunit leads to increased sensitivity to mechanical and inflammatory stimuli," Journal of Neuroscience, vol. 25, no. 43, pp. 9893-9901, 2005.

[120] A. M. Strassman, S. A. Raymond, and R. Burstein, "Sensitization of meningeal sensory neurons and the origin of headaches," Nature, vol. 384, no. 6609, pp. 560-564, 1996.

[121] J. Yan, R. M. Edelmayer, X. Wei, M. De Felice, F. Porreca, and G. Dussor, "Dural afferents express acid-sensing ion channels: a role for decreased meningeal $\mathrm{pH}$ in migraine headache," Pain, vol. 152, no. 1, pp. 106-113, 2011.

[122] J. Yan, X. Wei, C. Bischoff, R. M. Edelmayer, and G. Dussor, " $\mathrm{pH}$-evoked dural afferent signaling is mediated by ASIC3 and is sensitized by mast cell mediators," Headache: The 
Journal of Head and Face Pain, vol. 53, no. 8, pp. 1250-1261, 2013.

[123] D. Pietrobon and M. A. Moskowitz, "Chaos and commotion in the wake of cortical spreading depression and spreading depolarizations," Nature Reviews Neuroscience, vol. 15, no. 6, pp. 379-393, 2014.

[124] P. R. Holland, S. Akerman, A. P. Andreou, N. Karsan, J. A. Wemmie, and P. J. Goadsby, "Acid-sensing ion channel 1: a novel therapeutic target for migraine with aura," Annals of Neurology, vol. 72, no. 4, pp. 559-563, 2012.

[125] R. Schicho, W. Florian, I. Liebmann, P. Holzer, and I. T. Lippe, "Increased expression of TRPV1 receptor in dorsal root ganglia by acid insult of the rat gastric mucosa," European Journal of Neuroscience, vol. 19, no. 7, pp. 18111818, 2004.

[126] P. A. Hughes, S. M. Brierley, R. L. Young, and L. A. Blackshaw, "Localization and comparative analysis of acidsensing ion channel (ASIC1, 2, and 3) mRNA expression in mouse colonic sensory neurons within thoracolumbar dorsal root ganglia," Journal of Comparative Neurology, vol. 500, no. 5 , pp. 863-875, 2007.

[127] T. Wultsch, E. Painsipp, A. Shahbazian et al., "Deletion of the acid-sensing ion channel ASIC3 prevents gastritis-induced acid hyperresponsiveness of the stomach-brainstem axis," Pain, vol. 134, no. 3, pp. 245-253, 2008.

[128] A. J. Page, S. M. Brierley, C. M. Martin et al., "Different contributions of ASIC channels 1a, 2, and 3 in gastrointestinal mechanosensory function," Gut, vol. 54, no. 10, pp. 14081415, 2005.

[129] V. Milovic, "Polyamines in the gut lumen: bioavailability and biodistribution," European Journal of Gastroenterology \& Hepatology, vol. 13, no. 9, pp. 1021-1025, 2001.

[130] M. Fló, M. Margenat, L. Pellizza et al., "Functional diversity of secreted cestode Kunitz proteins: inhibition of serine peptidases and blockade of cation channels," PLoS Pathogens, vol. 13, no. 2, article e1006169, 2017.

[131] J. Tong, W. N. Wu, X. Kong et al., “Acid-sensing ion channels contribute to the effect of acidosis on the function of dendritic cells," The Journal of Immunology, vol. 186, no. 6, pp. 36863692, 2011.

[132] S. P. Sutherland, C. J. Benson, J. P. Adelman, and E. W. McCleskey, "Acid sensing ion channel 3 matches the acidgated current in cardiac ischemia-sensing neurons," Proceedings of the National Academy of Sciences, vol. 98, no. 2, pp. 711-716, 2001.

[133] T. Hattori, J. Chen, A. M. Harding et al., "ASIC2a and ASIC3 heteromultimerize to form $\mathrm{pH}$-sensitive channels in mouse cardiac dorsal root ganglia neurons," Circulation Research, vol. 105, no. 3, pp. 279-286, 2009.

[134] Z. G. Zhang, X. L. Zhang, X. Y. Wang, Z. R. Luo, and J. C. Song, "Inhibition of acid sensing ion channel by ligustrazine on angina model in rat," American Journal of Translational Research, vol. 7, no. 10, pp. 1798-1811, 2015.

[135] S. J. L. Flatters, "Characterization of a model of persistent postoperative pain evoked by skin/muscle incision and retraction," Pain, vol. 135, no. 1-2, pp. 119-130, 2008.

[136] H. J. Gerbershagen, E. Pogatzki-Zahn, S. Aduckathil et al., "Procedure-specific risk factor analysis for the development of severe postoperative pain," The Journal of the American Society of Anesthesiologists, vol. 120, no. 5, pp. 1237-1245, 2014.
[137] M. Gautam, C. J. Benson, and K. A. Sluka, "Increased response of muscle sensory neurons to decreases in $\mathrm{pH}$ after muscle inflammation," Neuroscience, vol. 170, no. 3, pp. 893-900, 2010.

[138] N. S. Gregory, A. L. Harris, C. R. Robinson, P. M. Dougherty, P. N. Fuchs, and K. A. Sluka, "An overview of animal models of pain: disease models and outcome measures," The Journal of Pain, vol. 14, no. 11, pp. 1255-1269, 2013.

[139] M. P. Price, S. L. McIlwrath, J. Xie et al., "The DRASIC cation channel contributes to the detection of cutaneous touch and acid stimuli in mice," Neuron, vol. 32, no. 6, pp. 1071-1083, 2001.

[140] K. A. Sluka, M. P. Price, J. A. Wemmie, and M. J. Welsh, "ASIC3, but not ASIC1, channels are involved in the development of chronic muscle pain," Progress in Pain Research, vol. 24, pp. 71-80, 2003.

[141] L. A. Frey Law, K. A. Sluka, T. McMullen, J. Lee, L. ArendtNielsen, and T. Graven-Nielsen, "Acidic buffer induced muscle pain evokes referred pain and mechanical hyperalgesia in humans," Pain, vol. 140, no. 2, pp. 254-264, 2008.

[142] R. Y. Walder, M. Gautam, S. P. Wilson, C. J. Benson, and K. A. Sluka, "Selective targeting of ASIC3 using miRNAs inhibits primary and secondary hyperalgesia following muscle inflammation," Pain, vol. 152, no. 10, pp. 23482356, 2011.

[143] R. Y. Walder, L. A. Rasmussen, J. D. Rainier, A. R. Light, J. A. Wemmie, and K. A. Sluka, "ASIC1 and ASIC3 play different roles in the development of hyperalgesia after inflammatory muscle injury," Journal of Pain, vol. 11, no. 3, pp. 210-218, 2010.

[144] W. N. Chen and C. C. Chen, "Acid mediates a prolonged antinociception via substance $\mathrm{P}$ signaling in acid-induced chronic widespread pain," Molecular Pain, vol. 10, no. 1, p. 30, 2014.

[145] K. A. Sluka and N. S. Gregory, "The dichotomized role for acid sensing ion channels in musculoskeletal pain and inflammation," Neuropharmacology, vol. 94, pp. 58-63, 2015.

[146] C. K. Glass, K. Saijo, B. Winner, M. C. Marchetto, and F. H. Gage, "Mechanisms underlying inflammation in neurodegeneration," Cell, vol. 140, no. 6, pp. 918-934, 2010.

[147] B. V. Zlokovic, "Neurovascular mechanisms of Alzheimer's neurodegeneration," Trends in Neuroscience, vol. 28, no. 4, pp. 202-208, 2005.

[148] D. Ding, S. I. Moskowitz, R. Li et al., "Acidosis induces necrosis and apoptosis of cultured hippocampal neurons," Experimental Neurology, vol. 162, no. 1, pp. 1-12, 2000.

[149] J. Z. Wang, L. Xi, G. F. Zhu et al., "The acidic pH-induced structural changes in Pin1 as revealed by spectral methodologies," Spectrochimica Acta Part A: Molecular and Biomolecular Spectroscopy, vol. 98, pp. 199-206, 2012.

[150] R. G. Parton, C. G. Dotti, R. Bacallao, I. Kurtz, K. Simons, and K. Prydz, " $\mathrm{pH}$-induced microtubule-dependent redistribution of late endosomes in neuronal and epithelial cells," The Journal of Cell Biology, vol. 113, no. 2, pp. 261-274, 1991.

[151] H. K. Kimelberg, E. Rutledge, S. Goderie, and C. Charniga, "Astrocytic swelling due to hypotonic or high $\mathrm{K}^{+}$medium causes inhibition of glutamate and aspartate uptake and increases their release," Journal of Cerebral Blood Flow \& Metabolism, vol. 15, no. 3, pp. 409-416, 1995.

[152] A. S. Bender, L. P. Young, and M. D. Norenberg, "Effect of lactic acid on L-glutamate uptake in cultured astrocytes: 
mechanistic considerations," Brain Research, vol. 750, no. 1, pp. 59-66, 1997.

[153] K. L. Tsai, S. M. Wang, C. C. Chen, T. H. Fong, and M. L. Wu, "Mechanism of oxidative stress-induced intracellular acidosis in rat cerebellar astrocytes and C6 glioma cells," Journal of Physiology, vol. 502, Part 1, pp. 161-174, 1997.

[154] C. H. Liu, F. Zhang, T. Krisrian, B. Polster, G. M. Fiskum, and B. $\mathrm{Hu}$, "Protein aggregation and multiple organelle damage after brain ischemia," in In Translational Stroke Research, pp. 101-116, Springer, New York, 2012.

[155] F. A. Gallagher, M. I. Kettunen, and K. M. Brindle, "Imaging $\mathrm{pH}$ with hyperpolarized 13C," NMR in Biomedicine, vol. 24, no. 8, pp. 1006-1015, 2011.

[156] M. Rango, C. Bonifati, and N. Bresolin, "Parkinson's disease and brain mitochondrial dysfunction: a functional phosphorus magnetic resonance spectroscopy study," Journal of Cerebral Blood Flow \& Metabolism, vol. 26, no. 2, pp. 283-290, 2006.

[157] M. M. Chaumeil, J. Valette, C. Baligand et al., "pH as a biomarker of neurodegeneration in Huntington's disease: a translational rodent-human MRS study," Journal of Cerebral Blood Flow \& Metabolism, vol. 32, no. 5, pp. 771-779, 2012.

[158] J. H. Cho and C. C. Askwith, "Potentiation of acid-sensing ion channels by sulfhydryl compounds," American Journal of Physiology-Cell Physiology, vol. 292, no. 6, pp. C2161C2174, 2007.

[159] J. M. Dawes, D. A. Anderson, D. L. H. Bennett, S. Bevan, and S. B. McMahon, "Inflammatory mediators and modulators of pain," Wall and Melzack's Textbook of Pain, vol. 5, pp. 48-67, 2013.

[160] A. Baron and E. Lingueglia, "Pharmacology of acid-sensing ion channels. Physiological and therapeutical perspectives," Neuropharmacology, vol. 94, pp. 19-35, 2015.

[161] F. González-Lizárraga, S. B. Socías, C. L. Ávila et al., "Repurposing doxycycline for synucleinopathies: remodelling of $\alpha$-synuclein oligomers towards non-toxic parallel beta-sheet structured species," Scientific Reports, vol. 7, article 41755, 2017.

[162] B. G. Peng, S. Ahmad, S. Chen, P. Chen, M. P. Price, and $\mathrm{X}$. Lin, "Acid-sensing ion channel 2 contributes a major component to acid-evoked excitatory responses in spiral ganglion neurons and plays a role in noise susceptibility of mice," Journal of Neuroscience, vol. 24, no. 45, pp. 1016710175, 2004.

[163] C. Huang, Z. L. Hu, W. N. Wu et al., "Existence and distinction of acid-evoked currents in rat astrocytes," Glia, vol. 58, no. 12, pp. 1415-1424, 2010.

[164] X. Su, Q. Li, K. Shrestha et al., "Interregulation of protongated $\mathrm{Na}^{+}$channel 3 and cystic fibrosis transmembrane conductance regulator," Journal of Biological Chemistry, vol. 281, no. 48, pp. 36960-36968, 2006.

[165] S. C. Grifoni, N. L. Jernigan, G. Hamilton, and H. A. Drummond, "ASIC proteins regulate smooth muscle cell migration," Microvascular Research, vol. 75, no. 2, pp. 202210, 2008.

[166] H. Jahr, M. Van Driel, G. J. Van Osch, H. Weinans, and J. P. van Leeuwen, "Identification of acid-sensing ion channels in bone," Biochemical and Biophysical Research Communications, vol. 337, no. 1, pp. 349-354, 2005.

[167] T. A. Richter, G. A. Dvoryanchikov, S. D. Roper, and N. Chaudhari, "Acid-sensing ion channel-2 is not necessary for sour taste in mice," Journal of Neuroscience, vol. 24, no. 16, pp. 4088-4091, 2004.

[168] J. A. Wemmie, J. Chen, C. C. Askwith et al., "The acidactivated ion channel ASIC contributes to synaptic plasticity, learning, and memory," Neuron, vol. 34, no. 3, pp. 463-477, 2002.

[169] J. A. Wemmie, C. C. Askwith, E. Lamani, M. D. Cassell, J. H. Freeman Jr., and M. J. Welsh, "Acid-sensing ion channel 1 is localized in brain regions with high synaptic density and contributes to fear conditioning," Journal of Neuroscience, vol. 23, no. 13, pp. 5496-5502, 2003.

[170] X. C. Weng, J. Q. Zheng, Q. E. Jin, and X. Y. Ma, "Inhibition of acid-induced apoptosis by targeting ASIC1a mRNA with short hairpin RNA," Acta Pharmacologica Sinica, vol. 28, no. 10, pp. 1621-1627, 2007.

[171] X. Li, F. R. Wu, R. S. Xu et al., "Acid-sensing ion channel la-mediated calcium influx regulates apoptosis of endplate chondrocytes in intervertebral discs," Expert Opinion on Therapeutic Targets, vol. 18, no. 1, pp. 1-14, 2014.

[172] B. Duan, L. J. Wu, Q. Yu et al., "Upregulation of acidsensing ion channel ASIC1a in spinal dorsal horn neurons contributes to inflammatory pain hypersensitivity," Journal of Neuroscience, vol. 27, no. 41, pp. 11139-11148, 2007.

[173] F. R. Wu, C. X. Pan, C. Rong et al., "Inhibition of acidsensing ion channel 1a in hepatic stellate cells attenuates PDGF-induced activation of HSCs through MAPK pathway," Molecular and Cellular Biochemistry, vol. 395, no. 1-2, pp. 199-209, 2014.

[174] D. Komnig, S. Imgrund, A. Reich, S. Gründer, and B. H. Falkenburger, "ASIC1a deficient mice show unaltered neurodegeneration in the subacute MPTP model of Parkinson disease," PLoS One, vol. 11, no. 11, article 0165235, 2016.

[175] H. K. Wong, P. O. Bauer, M. Kurosawa et al., "Blocking acid-sensing ion channel 1 alleviates Huntington's disease pathology via an ubiquitin-proteasome system-dependent mechanism," Human Molecular Genetics, vol. 17, no. 20, pp. 3223-3235, 2008.

[176] V. I. Pidoplichko, V. Aroniadou-Anderjaska, E. M. Prager et al., "ASIC1a activation enhances inhibition in the basolateral amygdala and reduces anxiety," Journal of Neuroscience, vol. 34, no. 9, pp. 3130-3141, 2014.

[177] M. W. Coryell, A. M. Wunsch, J. M. Haenfler et al., “Acidsensing ion channel-1a in the amygdala, a novel therapeutic target in depression-related behavior," Journal of Neuroscience, vol. 29, no. 17, pp. 5381-5388, 2009.

[178] M. Liu, A. A. Guo, C. Ghiathi, and Z. Xiong, "Acid-sensing ion channel 1a (ASIC1a) contributes to cell proliferation and migration caused by acidic environment in human glioma cells," in American Association for Cancer Research Annual Meeting, pp. 4058-4058, San Diego, CA, USA, 2014.

[179] S. Bhowmick, J. T. Moore, D. L. Kirschner et al., "Acidotoxicity via ASICla mediates cell death during oxygen glucose deprivation and abolishes excitotoxicity," ACS Chemical Neuroscience, vol. 8, no. 6, pp. 1204-1212, 2017.

[180] L. Liu and S. A. Simon, "Acidic stimuli activates two distinct pathways in taste receptor cells from rat fungiform papillae," Brain Research, vol. 923, no. 1-2, pp. 58-70, 2001.

[181] Z. Y. Tan, Y. Lu, C. A. Whiteis, C. J. Benson, M. W. Chapleau, and F. M. Abboud, "Acid-sensing ion channels contribute to transduction of extracellular acidosis in rat carotid body 
glomus cells," Circulation Research, vol. 101, no. 10, pp. 1009-1019, 2007.

[182] S. Ugawa, A. Inagaki, H. Yamamura et al., “Acid-sensing ion channel-1b in the stereocilia of mammalian cochlear hair cells," Neuroreport, vol. 17, no. 12, pp. 1235-1239, 2006.

[183] S. Dusenkova, F. Ru, L. Surdenikova et al., "The expression profile of acid-sensing ion channel (ASIC) subunits ASIC1a, ASIC1b, ASIC2a, ASIC2b, and ASIC3 in the esophageal vagal afferent nerve subtypes," American Journal of PhysiologyGastrointestinal and Liver Physiology, vol. 307, no. 9, pp. G922-G930, 2014.

[184] S. Ugawa, Y. Minami, W. Guo et al., "Receptor that leaves a sour taste in the mouth," Nature, vol. 395, no. 6702, p. 555, 1998.

[185] M. P. Price, G. R. Lewin, S. L. McIlwrath et al., "The mammalian sodium channel $\mathrm{BNC1}$ is required for normal touch sensation," Nature, vol. 407, no. 6807, pp. 10071011, 2000.

[186] Y. Lu, X. Ma, R. Sabharwal et al., "The ion channel ASIC2 is required for baroreceptor and autonomic control of the circulation," Neuron, vol. 64, no. 6, pp. 885-897, 2009.

[187] M. B. Johnson, K. Jin, M. Minami, D. Chen, and R. P. Simon, "Global ischemia induces expression of acid-sensing ion channel 2a in rat brain," Journal of Cerebral Blood Flow \& Metabolism, vol. 21, no. 6, pp. 734-740, 2001.

[188] L. J. Wu, B. Duan, Y. D. Mei et al., "Characterization of acidsensing ion channels in dorsal horn neurons of rat spinal cord," Journal of Biological Chemistry, vol. 279, no. 42, pp. 43716-43724, 2004.

[189] N. Ettaiche, P. Guy, M. Hofman, R. Lazdunski, and R. Waldmann, "Acid-sensing ion channel 2 is important for retinal function and protects against light-induced retinal degeneration," Journal of Neuroscience, vol. 24, no. 5, pp. 1005-1012, 2004.

[190] S. Ugawa, T. Yamamoto, T. Ueda et al., "Amiloride-insensitive currents of the acid-sensing ion channel-2a (ASIC2a)/ ASIC2b heteromeric sour-taste receptor channel," Journal of Neuroscience, vol. 23, no. 9, pp. 3616-3622, 2003.

[191] M. Ettaiche, E. Deval, S. Pagnotta, M. Lazdunski, and E. Lingueglia, "Acid-sensing ion channel 3 in retinal function and survival," Investigative Ophthalmology \& Visual Science, vol. 50, no. 5, pp. 2417-2426, 2009.

[192] K. Babinski, K. T. Lê, and P. Séguéla, "Molecular cloning and regional distribution of a human proton receptor subunit with biphasic functional properties," Journal of Neurochemistry, vol. 72, no. 1, pp. 51-57, 1999.

[193] A. Solé-Magdalena, E. G. Revuelta, I. Menénez-Díaz et al., "Human odontoblasts express transient receptor protein and acid-sensing ion channel mechanosensor proteins," Microscopy Research and Technique, vol. 74, no. 5, pp. 457463, 2011.

[194] M. Hoshikawa, A. Kato, H. Hojo et al., "Distribution of ASIC4 transcripts in the adult wild-type mouse brain," Neuroscience Letters, vol. 651, pp. 57-64, 2017.

[195] S. Gründer, H. S. Geissler, E. L. Bässler, and J. P. Ruppersberg, "A new member of acid-sensing ion channels from pituitary gland," Neuroreport, vol. 11, no. 8, pp. 1607-1611, 2000.

[196] S. Lilley, P. LeTissier, and J. Robbins, "The discovery and characterization of a proton-gated sodium current in rat retinal ganglion cells," Journal of Neuroscience, vol. 24, no. 5, pp. 1013-1022, 2004.
[197] E. Donier, F. Rugiero, C. Jacob, and J. N. Wood, "Regulation of ASIC activity by ASIC4-new insights into ASIC channel function revealed by a yeast two-hybrid assay," European Journal of Neuroscience, vol. 28, no. 1, pp. 7486, 2008.

[198] P. Escoubas, C. Bernard, G. Lambeau, M. Lazdunski, and H. Darbon, "Recombinant production and solution structure of PcTx1, the specific peptide inhibitor of ASIC1a protongated cation channels," Protein Science, vol. 12, no. 7, pp. 1332-1343, 2003.

[199] I. R. Chassagnon, C. A. McCarthy, Y. K. Y. Chin et al., "Potent neuroprotection after stroke afforded by a doubleknot spider-venom peptide that inhibits acid-sensing ion channel 1a," Proceedings of the National Academy of Sciences, vol. 114, no. 14, pp. 3750-3755, 2017.

[200] B. Chagot, P. Escoubas, S. Diochot, C. Bernard, M. Lazdunski, and H. Darbon, "Solution structure of APETx2, a specific peptide inhibitor of ASIC3 proton-gated channels," Protein Science, vol. 14, no. 8, pp. 2003-2010, 2005.

[201] D. I. Osmakov, S. A. Kozlov, Y. A. Andreev et al., "Sea anemone peptide with uncommon $\beta$-hairpin structure inhibits acid-sensing ion channel 3 (ASIC3) and reveals analgesic activity," Journal of Biological Chemistry, vol. 288, no. 32, pp. 23116-23127, 2013.

[202] A. A. Rodríguez, E. Salceda, A. G. Garateix et al., "A novel sea anemone peptide that inhibits acid-sensing ion channels," Peptides, vol. 53, pp. 3-12, 2014.

[203] A. Báez, E. Salceda, M. Fló et al., " $\alpha$-Dendrotoxin inhibits the ASIC current in dorsal root ganglion neurons from rat," Neuroscience Letters, vol. 606, pp. 42-47, 2015.

[204] A. Garateix, E. Salceda, R. Menéndez et al., "Antinociception produced by Thalassia testudinum extract BM-21 is mediated by the inhibition of acid sensing ionic channels by the phenolic compound thalassiolin B," Molecular Pain, vol. 7, no. 1, p. 10, 2011.

[205] M. A. Dubinnyi, D. I. Osmakov, S. G. Koshelev et al., "Lignan from thyme possesses inhibitory effect on ASIC3 channel current," Journal of Biological Chemistry, vol. 287, no. 39, pp. 32993-33000, 2012.

[206] F. Qiu, T. T. Liu, Z. W. Qu, C. Y. Qiu, Z. Yang, and W. P. Hu, "Gastrodin inhibits the activity of acid-sensing ion channels in rat primary sensory neurons," European Journal of Pharmacology, vol. 731, pp. 50-57, 2014.

[207] Z. W. Qu, T. T. Liu, C. Y. Qiu, J. D. Li, and W. P. Hu, "Inhibition of acid-sensing ion channels by chlorogenic acid in rat dorsal root ganglion neurons," Neuroscience Letters, vol. 567, pp. 35-39, 2014.

[208] Q. Cai, C. Y. Qiu, F. Qiu et al., "Morphine inhibits acidsensing ion channel currents in rat dorsal root ganglion neurons," Brain Research, vol. 1554, pp. 12-20, 2014.

[209] Y. Q. Liu, F. Qiu, C. Y. Qiu et al., "Cannabinoids inhibit acidsensing ion channel currents in rat dorsal root ganglion neurons," PloS One, vol. 7, no. 9, article e45531, 2012.

[210] N. Voilley, “Acid-sensing ion channels (ASICs): new targets for the analgesic effects of non-steroid anti-inflammatory drugs (NSAIDs)," Current Drug Targets-Inflammation \& Allergy, vol. 3, no. 1, pp. 71-79, 2004.

[211] D. Mango, G. Barbato, S. Piccirilli et al., "Electrophysiological and metabolic effects of CHF5074 in the hippocampus: protection against in vitro ischemia," Pharmacological Research, vol. 81, pp. 83-90, 2014. 
[212] T. Leng, J. Lin, J. E. Cottrell, and Z. G. Xiong, "Subunit and frequency-dependent inhibition of acid sensing ion channels by local anesthetic tetracaine," Molecular Pain, vol. 9, no. 1, p. 27, 2013.

[213] J. Lin, X. Chu, S. Maysami et al., "Inhibition of acid sensing ion channel currents by lidocaine in cultured mouse cortical neurons," Anesthesia and Analgesia, vol. 112, no. 4, pp. 977-981, 2011.

[214] Z. Lei, X. Li, G. Wang et al., "Inhibition of acid-sensing ion channel currents by propofol in rat dorsal root ganglion neurons," Clinical and Experimental Pharmacology and Physiology, vol. 41, no. 4, pp. 295-300, 2014.

[215] E. I. Nagaeva, N. N. Potapieva, and D. B. Tikhonov, "The effect of hydrophobic monoamines on acid-sensing ion channels ASIC1B," Acta Naturae (англоязычная версия), vol. 7, no. 2, p. 25, 2015.

[216] A. S. Agharkar and E. B. Gonzales, "4-Chlorophenylguanidine is an ASIC3 agonist and positive allosteric modulator," Journal of Pharmacological Sciences, vol. 133, no. 3, pp. 184-186, 2017.

[217] N. Boiko, V. Kucher, B. A. Eaton, and J. D. Stockand, "Inhibition of neuronal degenerin/epithelial $\mathrm{Na}^{+}$channels by the multiple sclerosis drug 4-aminopyridine," Journal of Biological Chemistry, vol. 288, no. 13, pp. 9418-9427, 2013.

[218] S. Ugawa, Y. Ishida, T. Ueda, K. Inoue, M. Nagao, and S. Shimada, "Nafamostat mesilate reversibly blocks acidsensing ion channel currents," Biochemical and Biophysical Research Communications, vol. 363, no. 1, pp. 203-208, 2007.

[219] X. Chen, L. Qiu, M. Li et al., "Diarylamidines: high potency inhibitors of acid-sensing ion channels," Neuropharmacology, vol. 58, no. 7, pp. 1045-1053, 2010.

[220] X. Li, J. Fei, Z. Lei et al., "Chloroquine impairs visual transduction via modulation of acid sensing ion channel 1a," Toxicology Letters, vol. 228, no. 3, pp. 200-206, 2014.

[221] G. Munro, J. K. Christensen, H. K. Erichsen et al., "NS383 selectively inhibits acid-sensing ion channels containing la and 3 subunits to reverse inflammatory and neuropathic hyperalgesia in rats," CNS Neuroscience \& Therapeutics, vol. 22, no. 2, pp. 135-145, 2016.

[222] N. Thongon, P. Ketkeaw, and C. Nuekchob, "The roles of acid-sensing ion channel $1 \mathrm{a}$ and ovarian cancer $\mathrm{G}$ proteincoupled receptor 1 on passive $\mathrm{Mg}^{2+}$ transport across intestinal epithelium-like Caco-2 monolayers," The Journal of Physiological Sciences, vol. 64, no. 2, pp. 129-139, 2014.

[223] Z. Xiong, Y. Liu, L. Hu, B. Ma, Y. Ai, and C. Xiong, “A rapid facilitation of acid-sensing ion channels current by corticosterone in cultured hippocampal neurons," Neurochemical Research, vol. 38, no. 7, pp. 1446-1453, 2013.

[224] S. J. Huang, W. S. Yang, Y. W. Lin, H. C. Wang, and C. C. Chen, "Increase of insulin sensitivity and reversal of agedependent glucose intolerance with inhibition of ASIC3," Biochemical and Biophysical Research Communications, vol. 371, no. 4, pp. 729-734, 2008.

[225] C. C. Askwith, C. Cheng, M. Ikuma, C. Benson, M. P. Price, and M. J. Welsh, "Neuropeptide FF and FMRFamide potentiate acid-evoked currents from sensory neurons and proton-gated DEG/ENaC channels," Neuron, vol. 26, no. 1, pp. 133-141, 2000.

[226] X. P. Chu, J. A. Wemmie, W. Z. Wang et al., "Subunit-dependent high-affinity zinc inhibition of acid-sensing ion channels," Journal of Neuroscience, vol. 24, no. 40, pp. 8678-8689, 2004.

[227] N. Kusama, A. M. Harding, and C. J. Benson, "Extracellular chloride modulates the desensitization kinetics of acidsensing ion channel 1a (ASIC1a)," Journal of Biological Chemistry, vol. 285, no. 23, pp. 17425-17431, 2010.

[228] X. M. Zha, R. Wang, D. Collier, P. M. Snyder, J. A. Wemmie, and M. J. Welsh, "Oxidant regulated inter-subunit disulfide bond formation between ASICla subunits," Proceedings of the National Academy of Sciences, vol. 106, no. 9, pp. 35733578, 2009.

[229] A. M. Ortega-Ramírez, Characterization of the Effect and Action Mechanism on ASIC Channels of Three Flavonoids Obtained from the Marine Grass Thalassia testudinum, Doctoral dissertation, Autonomous University of Puebla, Puebla, México, 2017. 


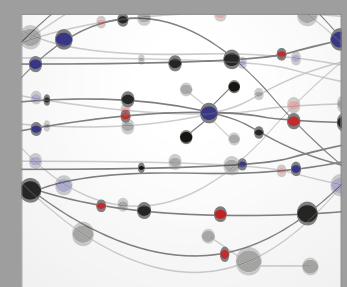

The Scientific World Journal
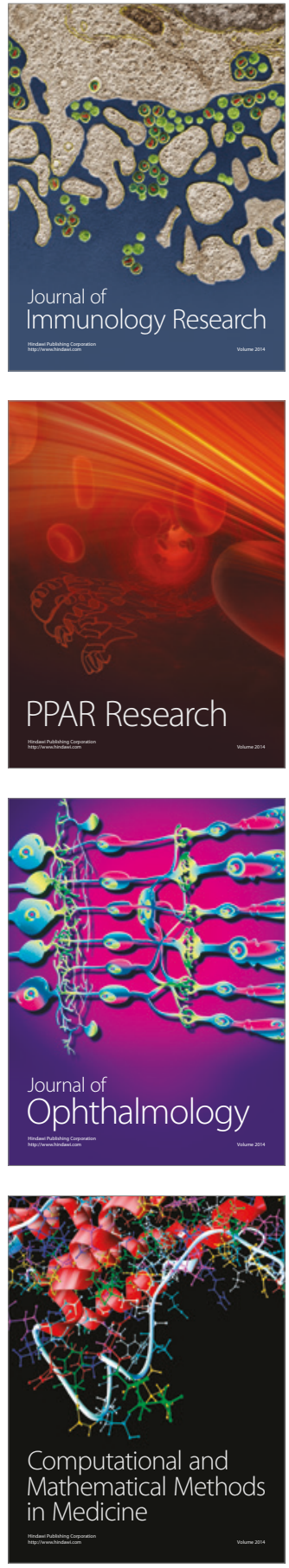

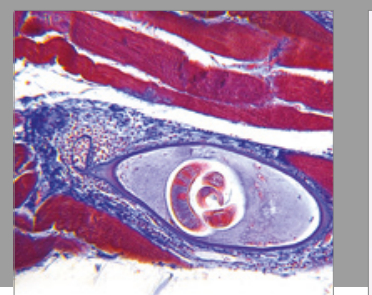

Gastroenterology Research and Practice
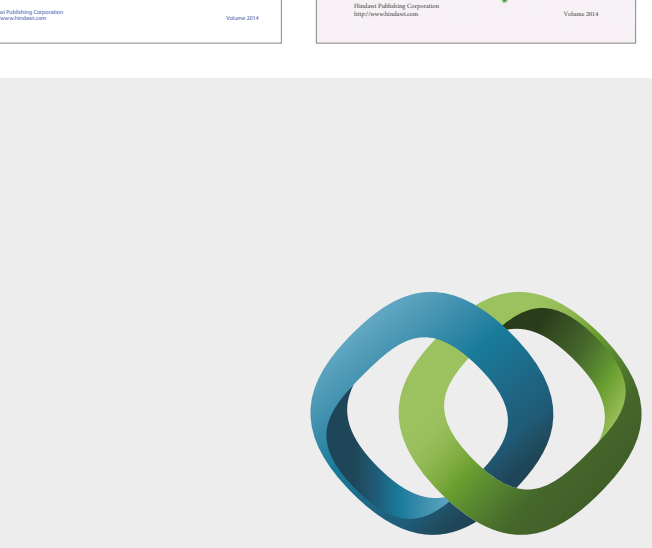

\section{Hindawi}

Submit your manuscripts at

https://www.hindawi.com
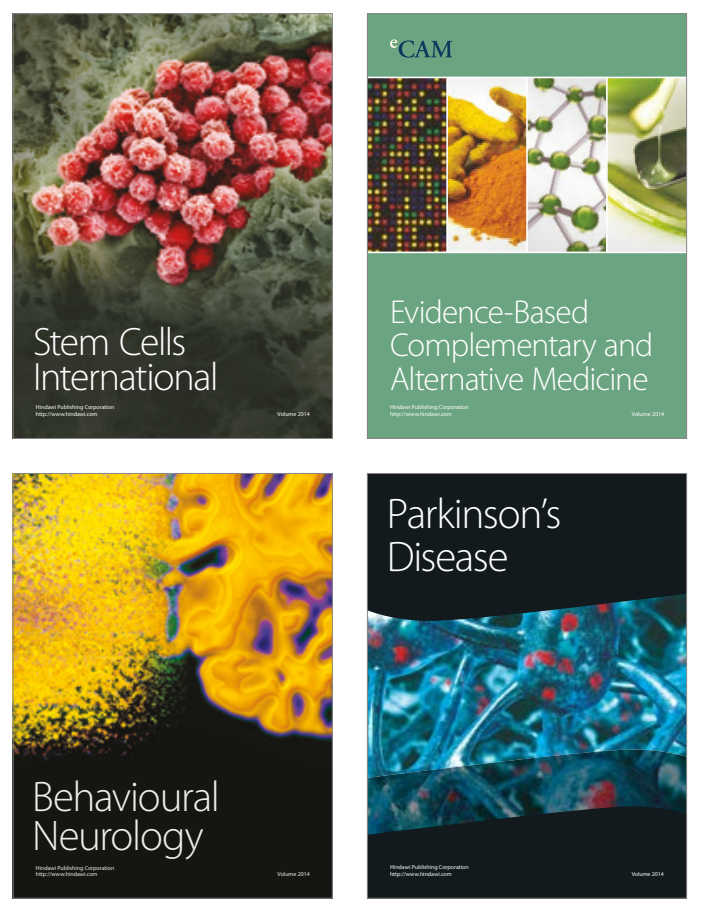
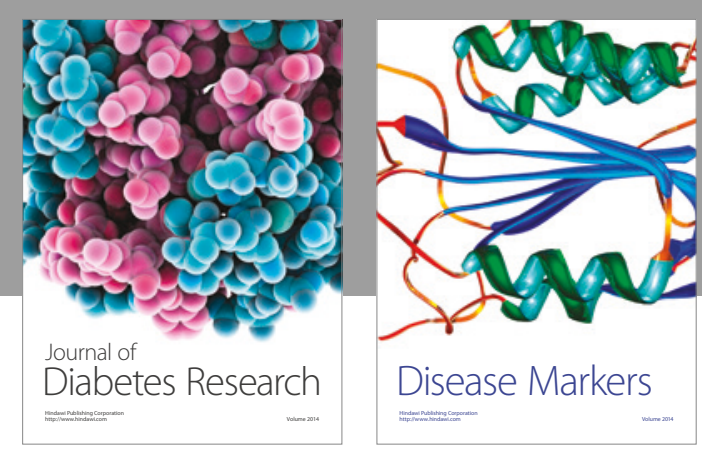

Disease Markers
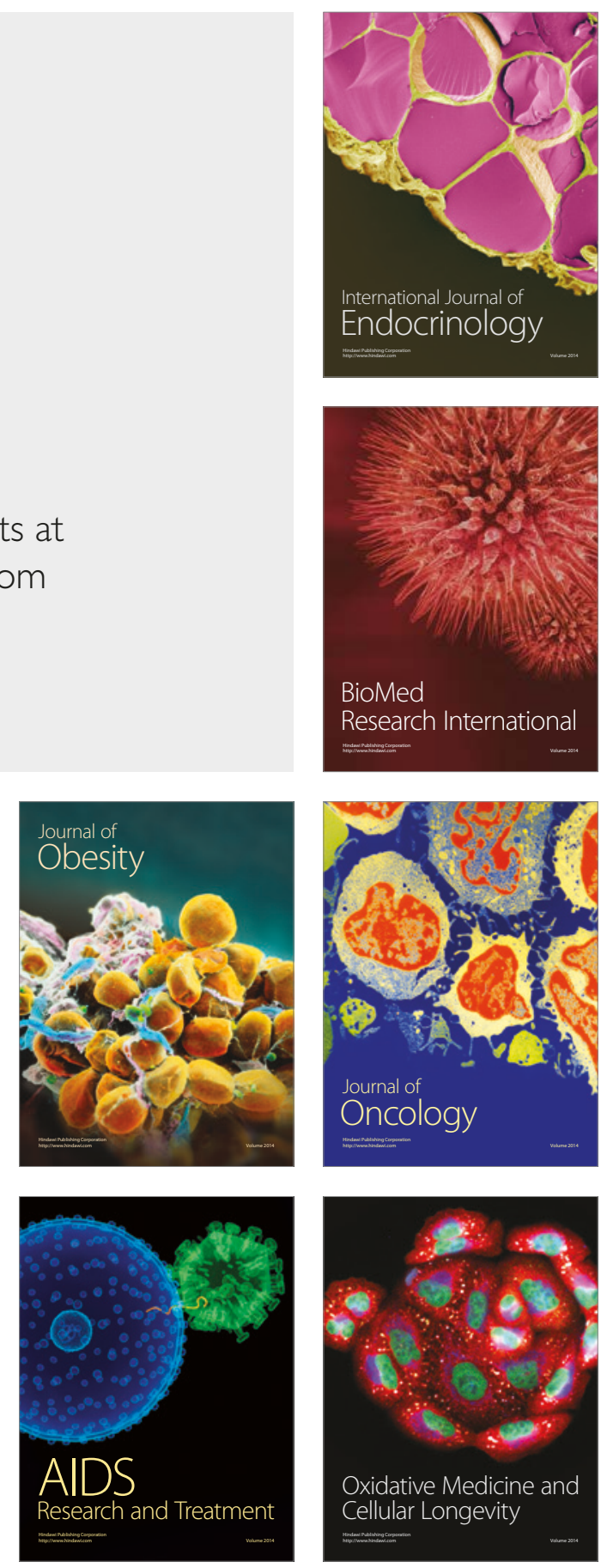